\title{
臭氧与干旱对植物复合影响的研究进展
}

\author{
高 峰 1,2 李 品 ${ }^{1}$ 冯兆忠 ${ }^{1,2 *}$
}

${ }^{1}$ 中国科学院生态环境研究中心城市与区域生态国家重点实验室, 北京 100085 ; ${ }^{2}$ 中国科学院大学, 北京 100049

摘 要 地表臭氧 $\left(\mathrm{O}_{3}\right)$ 农度和干旱频率的持续增加成为限制植物生长的重要因素。 $\mathrm{O}_{3}$ 通过气孔扩散进入植物组织内部, 产生 并积累活性氧(ROS)自由基, 促发细胞程序性死亡。干旱破坏植物抗氧化系统对ROS的解毒和修复功能, 导致ROS累积。两种 胁迫对植物的影响都是积累ROS并引发氧化胁迫, 使植物的光合作用和生理代谢机能受到限制, 最终阻碍植物生长, 导致生 物量降低。然而, $\mathrm{O}_{3}$ 和干旱胁迫对植物的复合效应可能是协同加重植物损伤, 也可能是拮抗减轻植物伤害, 二者的交互影响 存在复杂的作用过程。一方面, $\mathrm{O}_{3}$ 引起气孔响应滞后甚至失灵, 使植物对于两种胁迫的响应变得迟针, 进而加重植物的蒸散 失水和 $\mathrm{O}_{3}$ 毒害。另一方面, 干旱使植物气孔关闭, 从而降低对 $\mathrm{O}_{3}$ 的吸收量和水分蒸发, 但长期干旱限制 $\mathrm{CO}_{2}$ 的吸收, 最终导致 植物的生长受限。植物的响应过程不仅取决于两种胁迫作用的先后次序和持续时间, 而且受到植物本身生理代谢差异的影 响。该文结合国内外研究, 从气孔、光合碳代谢、抗氧化系统和生长发育等方面阐述了 $\mathrm{O}_{3}$ 和干旱胁迫对植物代谢调节和生长 发育的复合影响, 并提出了未来研究的发展方向。

关键词 臭氧; 干旱; 交互; 植物; 响应

引用格式: 高峰, 李品, 冯兆忠 (2017). 臭氧与干旱对植物复合影响的研究进展. 植物生态学报, 41, 252-268. doi: 10.17521/cjpe.2016.0195

\section{Interactive effects of ozone and drought stress on plants: A review}

\author{
GAO Feng ${ }^{1,2}$, LI Pin ${ }^{1}$, and FENG Zhao-Zhong ${ }^{1,2 *}$
}

${ }^{1}$ State Key Laboratory of Urban and Regional Ecology, Research Center for Eco-Environmental Sciences, Chinese Academy of Sciences, Beijing 100085, China; and ${ }^{2}$ University of Chinese Academy of Sciences, Beijing 100049, China

\section{Abstract}

Ground-level ozone $\left(\mathrm{O}_{3}\right)$ and drought are two key factors limiting plant growth. $\mathrm{O}_{3}$ can enter into the plant tissue through the stomata, then causing the formation of reactive oxygen species (ROS) which inspires programmed cell death. Drought usually induces the accumulation of ROS due to damage to antioxidant systems of plants. The effects of two kinds of stress on plants are similar due to the accumulation of ROS, resulting in reduced photosynthesis rate and physiological metabolism, eventually decreased plant growth and biomass. Nevertheless, $\mathrm{O}_{3}$ and drought interacts synergistically to accumulate detrimental effects or antagonistically to reduce harmful effects. Actually, it is complex interactive process between $\mathrm{O}_{3}$ and drought. On the one hand, $\mathrm{O}_{3}$ triggers stomatal sluggishness or even dysfunction, which exacerbates water transpiration of leaves, water loss from plants and further $\mathrm{O}_{3}$ phytotoxicity. On the other hand, drought induces stomatal closure, and thus protecting plants against the $\mathrm{O}_{3}$ influx and evaporation of water. However, prolonged drought could limit the uptake of $\mathrm{CO}_{2}$ and thus result in reduced plant growth. The response of plants to both $\mathrm{O}_{3}$ and drought not only depends on the occurring sequence and duration of any factor but also rely on the difference in physiological metabolism of the plant itself. The interactive effects of $\mathrm{O}_{3}$ and drought on stomatal characteristics, photosynthetic carbon mechanism, antioxidant response and growth development are reviewed in this paper and the aspects to be further studied are also suggested.

Key words $\mathrm{O}_{3}$; drought; interaction; plant; response

Citation: Gao F, Li P, Feng ZZ (2017). Interactive effects of ozone and drought stress on plants: A review. Chinese Journal of Plant Ecology, 41, 252-268. doi: 10.17521/cjpe.2016.0195

21世纪快速的都市化、工业化和交通运输使地 表臭氧 $\left(\mathrm{O}_{3}\right)$ 浓度逐渐增加, 世界各地出现不同程度
的 $\mathrm{O}_{3}$ 污染。其中, 英国、法国、德国、瑞士和意大 利等多个欧洲国家持续10天的 $\mathrm{O}_{3}$ 浓度都超过了 90

收稿日期Received: 2016-06-12 接受日期Accepted: 2016-12-16

* 通信作者Author for correspondence (E-mail: fzz@rcees.ac.cn) 
$\mathrm{nmol} \cdot \mathrm{mol}^{-1}$ (ICP Vegetation, 2011), 亚洲和拉丁美洲 等快速发展中国家的 $\mathrm{O}_{3}$ 平均浓度也超过 40 $\mathrm{nmol} \cdot \mathrm{mol}^{-1}$ (Matyssek et al., 2014)。在中国人口密集 的特大城市(如北京、上海、广州等) $\mathrm{O}_{3}$ 浓度超过 100 $\mathrm{nmol} \cdot \mathrm{mol}^{-1}$ (Chang \& Lee, 2006; Li et al., 2011), 预 计到2100年, 全球大部分地区的年平均 $\mathrm{O}_{3}$ 浓度将达 到 $40 \mathrm{nmol} \cdot \mathrm{mol}^{-1}$ 以上, 夏季北半球地区甚至将超过 $70 \mathrm{nmol} \cdot \mathrm{mol}^{-1}$ (Sitch et al., 2007)。地表 $\mathrm{O}_{3}$ 作为具有 植物毒性的空气污染物, 对自然植物种群、作物和 森林的危害被广泛关注(Matyssek \& Innes, 1999; Ashmore, 2005; Matyssek et al., 2012)。长时间暴露 于 $\mathrm{O}_{3}$ 下的敏感植物会出现表观可见的叶片伤害症 状(Mills et al., 2011; Feng et al., 2014), 并伴随光合 速率下降(Dizengremel, 2001; Renaut et al., 2009; Wittig et al., 2009), 生长缓慢及早衰(Matyssek \& Sandermann, 2003), 进而削弱植物的抗逆性、竞争 力和适应力, 最终降低碳汇潜力(Miller \& McBride, 1999; Karnosky et al., 2007; Edwards \& Zak, 2011), 对生态系统的结构、功能和碳循环产生长远影响。 现有的 $\mathrm{O}_{3}$ 污染可导致森林树种生物量损失达 $10 \%$, 农作物产量的损失为 5.3\%-17.5\% (Broadmeadow, 1998; Feng \& Kobayashi, 2009)。至2030年, 全球农 作物因 $\mathrm{O}_{3}$ 的影响年经济损失将高达170-350亿美元 (Avnery et al., 2011)。

随着人口增长以及农业、能源和工业部门的扩 增, 对水的需求也迅猛增加, 近年来不断发生的大 规模密集干旱事件在欧洲、非洲、亚洲、澳大利亚、 南美洲、中美洲和北美洲产生了广泛影响(Comte, 1998; Schubert et al., 2004; Dai, 2011)。1950-2010年 中国平均每年的受灾面积达到了 $21.6 \times 10^{6} \mathrm{hm}^{2}$ (邱 海军等, 2013)。干旱对植物的影响表现为: 降低气 孔导度、影响水分蒸散(Sadras \& Milroy, 1996; Bréda et al., 2006), 改变叶片光系统组分含量(Anjum et al., 2003), 损害光合反应器官(Fu \& Huang, 2001), 降低卡尔文循环的酶活性 (Monakhova \& Chernyadèv, 2002), 使植物的细胞分裂和增长受损 (Nonami, 1998), 限制叶片的数量, 缩减叶片的伸 张, 降低比叶面积(Abrams et al., 1994), 从而限制 植物生长, 最终导致产量降低(Schuppler et al., 1998; Monakhova \& Chernyadèv, 2002; Kaya et al., 2006)。中国在2006-2011年间, 由干早造成的直接 经济损失达到1 150亿元(中国水利部, 2006-2010;
国家统计局, 2007-2012)。气候变化导致的干旱使全 球森林在2000-2009年间减少了5.5亿T净初级生产 力(Zhao \& Running, 2010)。

政府间气候变化专门委员会(IPCC, 2013)报告 指出由气候变化导致的环境因素改变对生物体系有 直接、间接以及交互的影响。在植物旺盛生长的时期, 充足的光照和高温往往导致 $\mathrm{O}_{3}$ 浓度爆发性的升高, 并 常常伴随着干旱的发生, 从而使得植物同时受到高浓 度 $\mathrm{O}_{3}$ 和干旱的双重胁迫(Matyssek et al., 2010)。

目前, $\mathrm{O}_{3}$ 和干旱对植物的影响存在如下有争议 的结论: 一方面, $\mathrm{O}_{3}$ 引起的气孔滞后效应加重了植 物在干旱胁迫下的水分蒸散损失, 从而对植物产生 协同伤害(Grulke et al., 2003b; Karnosky et al., 2005); 另一方面, 干旱诱导气孔关闭, 限制进入叶 片的 $\mathrm{O}_{3}$ 剂量, 起到保护植物的拮抗作用, 降低了 $\mathrm{O}_{3}$ 伤害(Panek \& Goldstein, 2001; Panek et al., 2002; Grünhage \& Jager, 2003; Dizengremel et al., 2013); 也有一些研究显示二者胁迫下植物并不受交互作用 的影响(Le Thiec et al., 1994; Wittig et al., 2009)。在 $\mathrm{O}_{3}$ 暴露下, 干旱对植物的保护作用仅限于叶片水 平, 但对整株植物而言, 干旱的伤害大于 $\mathrm{O}_{3}$ 的伤害 (Alonson et al., 2014; Pollastrini et al., 2014)。此外, 由于 $\mathrm{O}_{3}$ 刺激糖基酶类基因表达促进了葡聚糖代谢, 而干旱则是抑制其代谢，导致两种胁迫下上述代谢 过程并没有受到影响(Iyer et al., 2013), 减轻了植物 在交互作用下所受到的伤害。因此, $\mathrm{O}_{3}$ 和干旱对植 物的伤害不仅取决于 $\mathrm{O}_{3}$ 进入细胞的量(Heath, 1994), 而且与植物通过酶类和非酶类反应去除氧自由基的 能力(Manderscheid et al., 1991)及自身防御和修复 过程的活跃度有关(Sandermann, 1996)。

深入了解 $\mathrm{O}_{3}$ 和干旱复合胁迫下植物的生长响 应机制对于理解陆地生态系统应对气候变化至关重 要。本文总结了2000-2016年间 $\mathrm{O}_{3}$ 和干旱交互作用 对植物影响的研究(表1)。发表的文章中, 欧美国家 达到71.0\%, 而中国只占14.6\%。虽然中国早在1974 年就由王勋陵和陈庆诚提出了 $\mathrm{O}_{3}$ 污染对植物的伤 害, 但是由于 20 世纪 90 年代国家治理的重点主要放 在一次污染物上, $\mathrm{O}_{3}$ 作为二次污染物直到2013年才 被环保部门纳入城市的空气质量监测指标。而国内 $\mathrm{O}_{3}$ 和干旱复合胁迫对植物影响的研究始于 $\mathrm{Xu}$ 等 (2007)对冬小麦(Triticum aestivum)的研究。鉴于前 人在 $\mathrm{O}_{3}$ (如许宏等, 2007 ; 寇太记等, 2009)或干旱 
表1 2000-2016年间 $\mathrm{O}_{3}$ 与干旱对复合植物影响的研究列表

Table 1 A list on the combined effects of ozone and drought on plants between 2000 and 2016

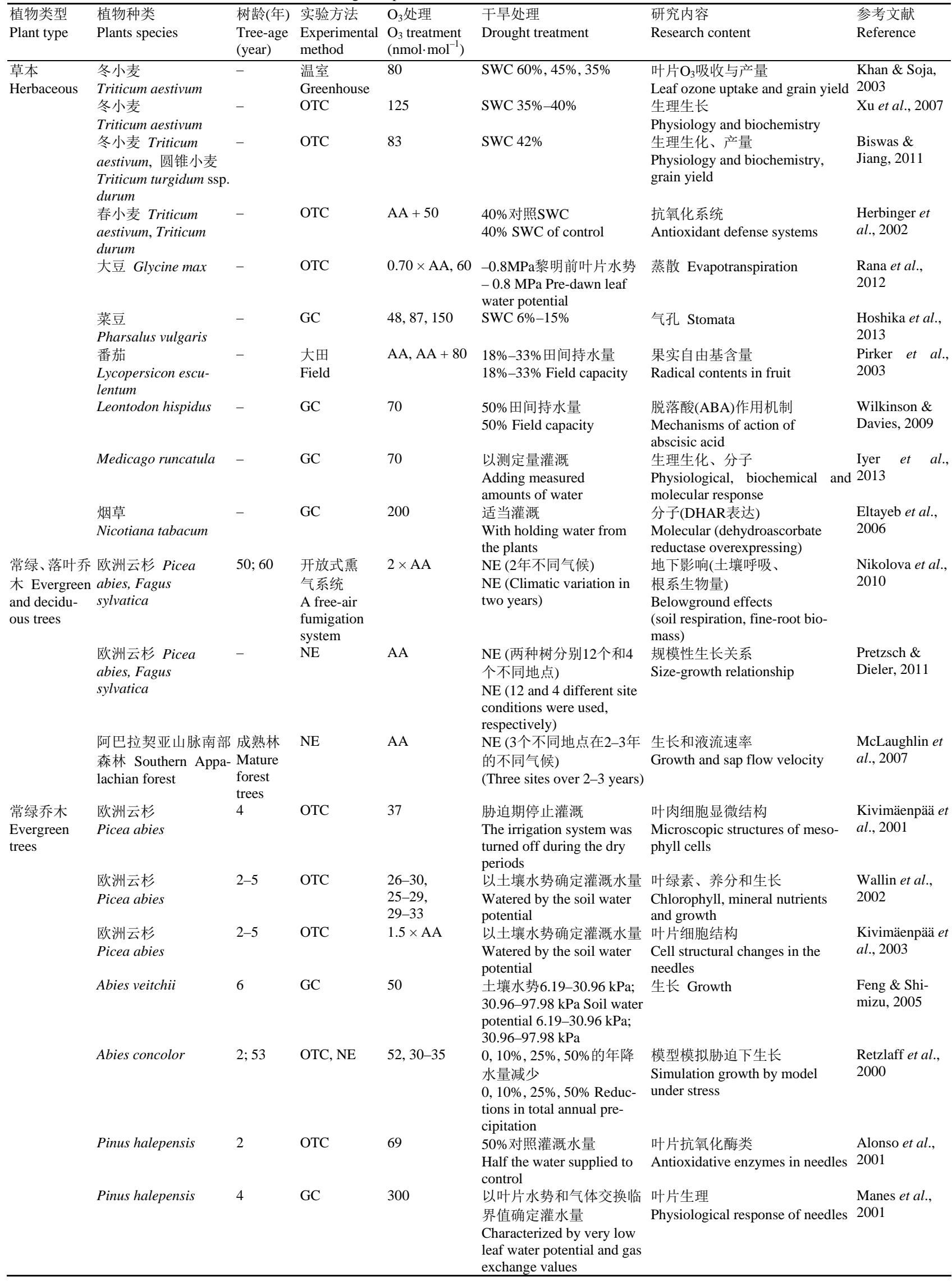


表1 (续) Table 1 (continued)

\begin{tabular}{|c|c|c|c|c|c|c|c|}
\hline $\begin{array}{l}\text { 植物类型 } \\
\text { Plant type }\end{array}$ & $\begin{array}{l}\text { 植物种类 } \\
\text { Plants species }\end{array}$ & $\begin{array}{l}\text { 树齡(年) } \\
\text { Tree-age } \\
\text { (year) }\end{array}$ & $\begin{array}{l}\text { 实验方法 } \\
\text { Experimental } \\
\text { method }\end{array}$ & $\begin{array}{l}\mathrm{O}_{3} \text { 处理 } \\
\mathrm{O}_{3} \text { treatment } \\
\left(\mathrm{nmol} \cdot \mathrm{mol}^{-1}\right)\end{array}$ & $\begin{array}{l}\text { 干旱处理 } \\
\text { Drought treatment }\end{array}$ & $\begin{array}{l}\text { 研究内容 } \\
\text { Research content }\end{array}$ & $\begin{array}{l}\text { 参考文献 } \\
\text { Reference }\end{array}$ \\
\hline \multirow[t]{9}{*}{$\begin{array}{l}\text { 常绿乔木 } \\
\text { Evergreen } \\
\text { trees }\end{array}$} & Pinus halepensis & 3 & $\overline{\mathrm{GC}}$ & 200 & $\begin{array}{l}100 \%-50 \% \text { 缓慢水分散失 } \\
\text { (中度); 以黎明前叶片水 } \\
\text { 势确定灌溉水量(重度) } \\
\text { From } 100 \% \text { to } 50 \% \text { of the } \\
\text { water loss by evapotranspi- } \\
\text { ration (mild); watered by } \\
\text { pre-dawn needle water } \\
\text { potential (intensity) }\end{array}$ & $\begin{array}{l}\text { 叶片酶(PEPC) } \\
\text { Phosphoenolpyruvatecarboxylase } \\
\text { in needles }\end{array}$ & $\begin{array}{l}\text { Fontaine et al., } \\
2003\end{array}$ \\
\hline & Pinus halepensis & 2 & OTC & $\mathrm{AA}+40$ & $\begin{array}{l}50 \% \text { 对照灌溉水量 } \\
\text { Half the water supplied to } \\
\text { control }\end{array}$ & $\begin{array}{l}\text { 生理生化补偿过程 } \\
\text { Compensation processes in } \\
\text { physiology and biochemistry }\end{array}$ & $\begin{array}{l}\text { Inclan et al., } \\
2005\end{array}$ \\
\hline & Quercus ilex & 3 & $\begin{array}{l}\text { 气候室 } \\
\text { Climatic } \\
\text { chambers }\end{array}$ & 250 & $\begin{array}{l}20 \mathrm{~mL} \text { 水每间隔一周灌溉 } \\
20 \mathrm{~mL} \text { of water per plant } \\
\text { every week }\end{array}$ & $\begin{array}{l}\text { 生理响应 } \\
\text { Physiogical responses }\end{array}$ & $\begin{array}{l}\text { Vitale et al., } \\
2008\end{array}$ \\
\hline & \multirow{2}{*}{$\begin{array}{l}\text { Quercus ilex ssp. ilex, } \\
\text { 长角豆 Ceratonia } \\
\text { siliqua } \\
\text { Quercus ilex ssp. ilex, } \\
\text { Q. ilex ssp. ballota }\end{array}$} & 1 & OTC & $37 ; 57$ & $\begin{array}{l}50 \% \text { 对照灌溉次数 } \\
\text { Half the watered times to } \\
\text { control }\end{array}$ & $\begin{array}{l}\text { 生理生化 } \\
\text { Physiology and biochemistry }\end{array}$ & $\begin{array}{l}\text { Ribas et al., } \\
2005\end{array}$ \\
\hline & & $1-2$ & OTC & $31 ; 49$ & $\begin{array}{l}50 \% \text { 对照灌溉水量 } \\
\text { Half the water supplied to } \\
\text { control }\end{array}$ & $\begin{array}{l}\text { 气体交换、生长和生物量 } \\
\text { Gas exchange, growth and bio- } \\
\text { mass }\end{array}$ & $\begin{array}{l}\text { Alonso et al., } \\
2014\end{array}$ \\
\hline & $\begin{array}{l}\text { 西黄松 } \\
\text { Pinus ponderosa } \\
\text { 西黄松 }\end{array}$ & $6-8$ & $\mathrm{NE}$ & $40-70$ & NE & $\begin{array}{l}\mathrm{O}_{3} \text { 和碳吸收 } \\
\mathrm{O}_{3} \text { and carbon uptake }\end{array}$ & \multirow{2}{*}{$\begin{array}{l}\text { Panek \& Gold- } \\
\text { stein, } 2001 \\
\text { Grulke et al., } \\
2002\end{array}$} \\
\hline & $\begin{array}{l}\text { 西黄松 } \\
\text { Pinus ponderosa }\end{array}$ & 40 & $\mathrm{NE}$ & $\begin{array}{l}58-60 \\
64-67,80\end{array}$ & $\begin{array}{l}\text { 黎明前木质部水势 }<-1.2 \\
\text { MPa Xylem potentials } \\
<-1.2 \text { MPa at predawn }\end{array}$ & $\begin{array}{l}\text { 碳获取 } \\
\text { Carbon acquisition }\end{array}$ & \\
\hline & $\begin{array}{l}\text { 西黄松 } \\
\text { Pinus ponderosa }\end{array}$ & $5-7$ & $\mathrm{NE}$ & 53 & $\begin{array}{l}\mathrm{NE}(2 \text { 年不同气候) } \\
\text { NE (Climatic variation in } \\
\text { two years) }\end{array}$ & $\begin{array}{l}\mathrm{O}_{3} \text { 暴露度量参数 } \\
\mathrm{O}_{3} \text { exposure metrics parameters }\end{array}$ & $\begin{array}{l}\text { Panek et al., } \\
2002\end{array}$ \\
\hline & $\begin{array}{l}\text { 西黄松 } \\
\text { Pinus ponderosa }\end{array}$ & 7 & $\mathrm{NE}$ & AA & $\begin{array}{l}\text { NE (4个不同地点) } \\
\text { NE (Four sites) }\end{array}$ & $\begin{array}{l}\text { 吸收模型参数 Parameters for } \mathrm{O}_{3} \\
\text { uptake modeling }\end{array}$ & Panek, 2004 \\
\hline $\begin{array}{l}\text { 落叶乔木 } \\
\text { Deciduous } \\
\text { trees }\end{array}$ & $\begin{array}{l}\text { 海南蒲桃 Syzygium } \\
\text { hainanense, 糖胶树 } \\
\text { Alstonia scholaris }\end{array}$ & $\begin{array}{l}\text { 当年 } \\
\text { Current } \\
\text { year }\end{array}$ & OTC & 75 & $\begin{array}{l}40 \%-50 \% \text { 土壤相对含水量 } \\
40 \%-50 \% \text { Relative soil } \\
\text { water content }\end{array}$ & $\begin{array}{l}\text { 光合生理 } \\
\text { Photosynthetic physiology }\end{array}$ & $\begin{array}{l}\text { Hao et al., } \\
2014\end{array}$ \\
\hline & $\begin{array}{l}\text { 长芒杜英 Elaeocarpus } \\
\text { apiculatus, 壳菜果 } \\
\text { Mytilaria laosensis,黧 } \\
\text { 蒴雉 Castanopsis fissa }\end{array}$ & $\begin{array}{l}\text { 当年 } \\
\text { Current } \\
\text { year }\end{array}$ & OTC & 150 & $\begin{array}{l}50 \% \text { 对照灌溉次数 } \\
\text { Half the watered times to } \\
\text { control }\end{array}$ & $\begin{array}{l}\text { 苂光生理 } \\
\text { Chlorophyll } a \text { fluorescence }\end{array}$ & Li et al., 2015 \\
\hline & $\begin{array}{l}\text { 醉香含笑 Michelia } \\
\text { macclurei, 樟 } \\
\text { Cinnamomum cam- } \\
\text { phora, 红花荷 } \\
\text { Rhodoleia championii, } \\
\text { 壳菜果 Mytilaria } \\
\text { laosensis }\end{array}$ & 1 & OTC & 20 & $\begin{array}{l}\text { 两天一次灌溉 } \\
\text { Watered once in two days }\end{array}$ & $\begin{array}{l}\text { 根、茎、叶和总生物量及根茎比 } \\
\text { Root biomass, stem biomass, leaf } \\
\text { biomass, total biomass and } \\
\text { root/shoot ratio }\end{array}$ & Ye et al., 2014 \\
\hline & Fagus crenata & 3 & GC & 60 & $\begin{array}{l}70 \% \text { 对照灌溉水量 } 70 \% \\
\text { Water supplied to control }\end{array}$ & $\begin{array}{l}\text { 叶片物候和芽抗寒性 } \\
\text { Leaf phenological characteristics } \\
\text { and bud frost hardiness }\end{array}$ & $\begin{array}{l}\text { Yonekura et } \\
\text { al., } 2004\end{array}$ \\
\hline & Fagus crenata & 3 & GC & 60 & $\begin{array}{l}70 \% \text { 对照 灌溉水量 } 70 \% \\
\text { Water supplied to control }\end{array}$ & $\begin{array}{l}\text { 叶片抗氧化系统 } \\
\text { Leaf antioxidative systems }\end{array}$ & $\begin{array}{l}\text { Watanabe et } \\
\text { al., } 2005\end{array}$ \\
\hline & Fagus sylvatica & 60 & $\mathrm{NE}$ & $2 \times \mathrm{AA}$ & $\begin{array}{l}\mathrm{NE} \text { (3年不同气候) } \\
\mathrm{NE} \text { (Climatic variation in } \\
\text { three years) }\end{array}$ & $\begin{array}{l}\text { 生理生化 } \\
\text { Physiology and biochemistry }\end{array}$ & $\begin{array}{l}\text { Löw et al., } \\
2006\end{array}$ \\
\hline & Fagus sylvatica & 60 & $\mathrm{NE}$ & $2 \times \mathrm{AA}$ & $\begin{array}{l}\mathrm{NE} \text { ( } 2 \text { 年不同气候) } \\
\mathrm{NE} \text { (Climatic variation in } \\
\text { two years) }\end{array}$ & $\begin{array}{l}\text { 细根抗氧化物 } \\
\text { Antioxidants in fine roots }\end{array}$ & $\begin{array}{l}\text { Haberer et al., } \\
2008\end{array}$ \\
\hline & Fagus sylvatica & - & $\mathrm{NE}$ & AA & $\begin{array}{l}\text { NE (9个不同地点) } \\
\text { NE (Nine sites) }\end{array}$ & $\begin{array}{l}\text { 日生长 } \\
\text { Daily growth }\end{array}$ & $\begin{array}{l}\text { Kuehn et al., } \\
2015\end{array}$ \\
\hline & $\begin{array}{l}\text { Fagus sylvatica, } \\
\text { 夏栋 Quercus robur, } \\
\text { 辽杨×中东杨 Popu- } \\
\text { lus maximowiczii × } \\
\text { P. berolinensis }\end{array}$ & 1 & OTC & $0.95 \times \mathrm{AA}$ & $\begin{array}{l}\text { 50\%田间持水量 } \\
\text { 50\% Field capacity }\end{array}$ & $\begin{array}{l}\text { 生长和生理响应 } \\
\text { Growth and physiological re- } \\
\text { sponses }\end{array}$ & $\begin{array}{l}\text { Pollastrini et } \\
\text { al., } 2010\end{array}$ \\
\hline & $\begin{array}{l}\text { 岳桦 } \\
\text { Betula ermanii }\end{array}$ & 2 & GC & 50 & $\begin{array}{l}\text { 土壤水势 } 6.19-30.96 \mathrm{kPa} \text {, } \\
30.96-97.98 \mathrm{kPa} \text { Soil water } \\
\text { potential 6.19-30.96 kPa, } \\
30.96-97.98 \mathrm{kPa}\end{array}$ & $\begin{array}{l}\text { 生长、生理生化 Growth、 } \\
\text { physiology and biochemistry }\end{array}$ & $\begin{array}{l}\text { Shimizu \& } \\
\text { Feng, } 2007\end{array}$ \\
\hline & $\begin{array}{l}\text { 元宝棫 } \\
\text { Acer truncatum }\end{array}$ & 1 & OTC & $102-147$ & $\begin{array}{l}40 \%-50 \% \text { 田间持水量 } \\
40 \%-50 \% \text { Field capacity }\end{array}$ & 气孔响应 Stomatal response & $\begin{array}{l}\text { Wen et al., } \\
2014\end{array}$ \\
\hline & $\begin{array}{l}\text { 元宝棫 } \\
\text { Acer truncatum }\end{array}$ & 1 & ОTC & $102-147$ & $\begin{array}{l}40 \%-50 \% \text { 田间持水量 } \\
40 \%-50 \% \text { Field capacity }\end{array}$ & $\begin{array}{l}\text { 生长和生理 Growth and physi- } \\
\text { ology }\end{array}$ & Li et al., 2015 \\
\hline
\end{tabular}




\begin{tabular}{|c|c|c|c|c|c|c|c|}
\hline $\begin{array}{l}\text { 植物类型 } \\
\text { Plant type }\end{array}$ & $\begin{array}{l}\text { 植物种类 } \\
\text { Plants species }\end{array}$ & $\begin{array}{l}\text { 树龄(年) } \\
\text { Tree-age } \\
\text { (year) }\end{array}$ & $\begin{array}{l}\text { 实验方法 } \\
\text { Experimental } \\
\text { method }\end{array}$ & $\begin{array}{l}\mathrm{O}_{3} \text { 处理 } \\
\mathrm{O}_{3} \text { treatment } \\
\left(\mathrm{nmol} \cdot \mathrm{mol}^{-1}\right)\end{array}$ & $\begin{array}{l}\text { 干旱处理 } \\
\text { Drought treatment }\end{array}$ & $\begin{array}{l}\text { 研究内容 } \\
\text { Research content }\end{array}$ & $\begin{array}{l}\text { 参考文献 } \\
\text { Reference }\end{array}$ \\
\hline \multirow[t]{4}{*}{$\begin{array}{l}\text { 落叶乔木 } \\
\text { Deciduous } \\
\text { trees }\end{array}$} & $\begin{array}{l}\text { 辽杨 } \times \text { 中东杨 Popu- } \\
\text { lus maximowiczii } \times P \text {. } \\
\text { berolinensis }\end{array}$ & $\begin{array}{l}\text { 当年 } \\
\text { Current } \\
\text { year }\end{array}$ & OTC & $0.95 \times \mathrm{AA}$ & $\begin{array}{l}150 \mathrm{~mL} \text { 水每天灌溉 } \\
150 \mathrm{~mL} \text { of water a day }\end{array}$ & $\begin{array}{l}\text { 不同冠层叶绿素苂光 Chloro- } \\
\text { phyll } a \text { fluorescence along a } \\
\text { crown }\end{array}$ & $\begin{array}{l}\text { Desotgiu et al., } \\
2012\end{array}$ \\
\hline & $\begin{array}{l}\text { 辽杨 } \times \text { 中东杨 Popu- } \\
\text { lus maximowiczii } \times P \text {. } \\
\text { berolinensis }\end{array}$ & $\begin{array}{l}\text { 当年 } \\
\text { Current } \\
\text { year }\end{array}$ & OTC & $0.95 \times \mathrm{AA}$ & $\begin{array}{l}150 \mathrm{~mL} \text { 水每天灌溉 } \\
150 \mathrm{~mL} \text { water a day }\end{array}$ & $\begin{array}{l}\text { 光合、生长和同位素 Photo- } \\
\text { synthesis、growth and stable } \\
\text { isotope }\end{array}$ & $\begin{array}{l}\text { Pollastrini et } \\
\text { al., } 2013\end{array}$ \\
\hline & $\begin{array}{l}\text { 欧洲山杨×银白杨 } \\
\text { Populus tremula ×P. } \\
\text { alba }\end{array}$ & $\begin{array}{l}\text { 当年 } \\
\text { Current } \\
\text { year }\end{array}$ & GC & $C F+120$ & SWC 35\% & $\begin{array}{l}\text { 生理、蛋白质组 Physiological } \\
\text { and proteomic }\end{array}$ & $\begin{array}{l}\text { Bohler et al., } \\
2013\end{array}$ \\
\hline & $\begin{array}{l}\text { 辽杨 } \times \text { 中东杨 Popu- } \\
\text { lus maximowiczii } \times P \text {. } \\
\text { berolinensis }\end{array}$ & $\begin{array}{l}\text { 当年 } \\
\text { Current } \\
\text { year }\end{array}$ & OTC & $44-53$ & $\begin{array}{l}60 \%, 20 \% \text { 对照灌溉水量 } \\
60 \%, 20 \% \text { Water respect } \\
\text { to control }\end{array}$ & $\begin{array}{l}\text { 生理生化、生长和同位素 } \\
\text { Physiological and biochemistry、 } \\
\text { biomass and isotope }\end{array}$ & $\begin{array}{l}\text { Pollastrini et } \\
\text { al., } 2014\end{array}$ \\
\hline
\end{tabular}

OTC, 开顶气室; AA, 环境浓度; CF, 过滤空气; NF, 未过滤空气; CF /NF+, 过滤/未过滤空气再加一定浓度臭氧; GC, 生长室; NE, 自然生长环境; SWC, 土壤含水量。

OTC, open top chamber; AA, ambient air; CF, charcoal-filtered air; NF, non-filtered air; CF/NF+, charcoal-filtered/non-filtered air + extra ozone; GC, growth chamber; NE, natural environment; SWC, soil water capacity.

(如孙梅霞等, 2004; 田汉勤等, 2007; 杨帆等, 2007) 单因子胁迫对植物的影响方面已有大量阐述，本文 在总结国内外 $\mathrm{O}_{3}$ 和干旱复合影响的研究理论和结 果的基础上，深入探讨此两种胁迫交互作用条件下 植物的响应机制及响应过程, 旨在明确植物如何应 对由气候变化导致的 $\mathrm{O}_{3}$ 和干旱两种胁迫, 同时指出 未来需要侧重的研究方向。

\section{1 臭氧和干旱对植物的复合影响}

\section{1 植物的气孔导度响应}

气孔是植物体与外界环境进行气体交换的门 户, 通过控制 $\mathrm{CO}_{2}$ 和水分对蒸滕、光合、呼吸等重要 生理过程进行调节, 也是诸如 $\mathrm{O}_{3}$ 等气体污染物进入 植物的主要通道。气孔调节的首要功能是平衡与碳 收支相关的水分消耗(Cowan, 1978)。植物应对 $\mathrm{O}_{3}$ 和 干旱胁迫的最初防御门户就是气孔。 $\mathrm{O}_{3}$ 在通过气孔 进入植物的同时伴随水汽的蒸发, 气孔关闭的响应 机制理论上会保护植物抵抗这两种胁迫, 形成物理 防御抵制 $\mathrm{O}_{3}$ 吸收和水汽的散失(图1)。渐进式(progressive)的土壤干旱阻碍了植物对 $\mathrm{O}_{3}$ 的吸收(Panek et al., 2002; Matyssek et al., 2006)。Ciais等(2005)的 结果显示, 即使 $\mathrm{O}_{3}$ 浓度在增加了 $40 \%$ 的严重胁迫下, 由于初夏的干旱迫使气孔关闭, 植物对 $\mathrm{O}_{3}$ 的吸收仍 低于潮湿年份的平均吸收值。据此一些田间限制性 灌溉的保护措施也在实际中得到应用。例如古巴农 民在预防夏季 $\mathrm{O}_{3}$ 浓度升高对作物的毒害方面，通过 提前1-2天控制对叶类作物(莫芭(Lactuca sativa)和 烟草(Nicotiana tabacum))的灌溉，成功地降低了 $\mathrm{O}_{3}$ 带来的伤害(ICP Vegetation, 2011)。然而, 此种方法



图1 气孔在臭氧与干旱胁迫下的调节。

Fig. 1 Regulation of the stomata under the condition of $\mathrm{O}_{3}$ and drought.

仅针对一些在干旱胁迫下表现出诸如气孔关闭和叶 表面积减少的品种才是有效的(ICP Vegetation, 2011)。在大气和土壤都潮湿的环境中, 即使暴露在 低浓度 $\mathrm{O}_{3}$ 下，通过气孔进入到植物的 $\mathrm{O}_{3}$ 通量也是较 高的; 而在水分缺乏的环境中, 即使在高浓度 $\mathrm{O}_{3}$ 条 件下，干旱诱导的气孔关闭仍极大地限制了植物对 $\mathrm{O}_{3}$ 的吸收(Retzlaff et al., 2000; Paoletti, 2006)。而且 干旱对气孔导度和 $\mathrm{O}_{3}$ 吸收的限制有记忆效应 (memory-effects) (Karlsson et al., 2000)。可见气孔内 在行为机制的改变可能是为了降低 $\mathrm{O}_{3}$ 胁迫引起的 植物细胞壁木质化和膜损伤(Heath \& Taylor, 1997; Maier-Maercker, 1998)。但干旱条件下的气孔关闭虽 然降低了植物对 $\mathrm{O}_{3}$ 的吸收, 同时也限制了植物对 $\mathrm{CO}_{2}$ 的吸收(Panek \& Goldstein, 2001), 进而影响植 物生长。气孔的响应(关闭)也并不是始终如一的 (Wittig et al., 2007), 如 $\mathrm{O}_{3}$ 诱发的气孔反应滞后 (sluggish)(Paoletti \& Grulke, 2010; Hoshika et al., 2012, 2014; Dumont et al., 2013)所导致的气孔关闭 缓慢(Pearson \& Mansfield, 1993; Karlsson et al., 1995)或气孔导度增大(Oksanen, 2003), 降低了气孔 
在干旱条件下对蒸腾的抑制, 从而扰乱了植物对水 分亏缺的响应(Hoshika et al., 2014), 导致 $\mathrm{O}_{3}$ 和干旱 交互作用下植物的伤害加重(Retzlaff et al., 2000; Pollastrini et al., 2010)。这种气孔在时间上的滞后效 应与植物物种品种(Paoletti \& Grulke, 2010; Hoshika et al., 2012)、胁迫的程度(Hoshika et al., 2012)及季 节的变化有关(Hoshika et al., 2014)。

$\mathrm{O}_{3}$ 和干旱交互作用下, 干旱诱导的气孔关闭被 认为是保护植物免受 $\mathrm{O}_{3}$ 伤害的防御措施。干旱条件 下种植园的西黄松(Pinus ponderosa)也显示 $\mathrm{O}_{3}$ 伤害 的短期保护效应(Panek \& Goldstein, 2001)。然而, 这一现象尚未得到普遍证实。尽管干旱诱导的气孔 关闭降低了植物对 $\mathrm{O}_{3}$ 的吸收, 但干旱胁迫同时也增 加了叶片的自由基(Buckland et al., 1991; Biehler \& Fock, 1996), 使植物受到伤害, 因而干旱和 $\mathrm{O}_{3}$ 的复 合胁迫对植物可能是有害的(Heber et al., 1995)。自 然环境中 $\mathrm{O}_{3}$ 与干旱对气孔的交互作用取决于品种 (Pell et al., 1993; Ribas et al., 2005; Biswas \& Jiang, 2011; Wagg et al., 2012)、胁迫出现次序(Bohler et al., 2013)、胁迫程度(Le Thiec et al., 1994)、一天内胁迫 的时段 (Le Thiec et al., 1994)、植物的生长期 (Alonso et al., 2001; Skärby et al., 1998)以及季节的 变化(Pell et al., 1993)。对 $\mathrm{O}_{3}$ 敏感的冬小麦品种, 在 $\mathrm{O}_{3}$ 和干旱的交互作用下显示出对 $\mathrm{O}_{3}$ 的抗性; 然而另 一抗性品种(Triticum turgidum ssp. durum)则丧失了 对 $\mathrm{O}_{3}$ 的抗性(Biswas \& Jiang, 2011)。两种胁迫发生的 次序对交互作用也至关重要(Le Thiec et al., 1994; Bohler et al., 2013)。如果干旱发生在 $\mathrm{O}_{3}$ 胁迫之前, 干旱首先促发气孔导度关闭, 进而保护了随后发生 的 $\mathrm{O}_{3}$ 对植物的伤害。有实验证实 $\mathrm{O}_{3}$ 暴露下的 Leontodon hispidus施用外源脱落酸(ABA)后, 渐进 的干旱胁迫会降低气孔导度(Wilkinson \& Davies, 2009), 通过干旱影响气孔对ABA的敏感性和离子 泵, 降低了细胞的膜损伤(Torsethaugen et al., 1999), 减轻了植物的伤害程度。而当干旱发生在 $\mathrm{O}_{3}$ 胁迫之 后, 因ABA诱导的气孔关闭被 $\mathrm{O}_{3}$ 诱导植物释放的乙 烯引起的气孔缓慢响应所抑制(Tanaka et al., 2005), 导致的气孔滞后效应加重了干旱对植物的伤害 (Wilkinson \& Davies, 2009)。但也有科学家指出干早 诱导的 $A B A$ 对气孔在 $O_{3}$ 胁迫下的敏感程度的影响 仍未明确(Wilkinson \& Davies, 2010)。

综上所述, 植物的气孔响应取决于发生胁迫的
时期和两种胁迫交互作用的强度: 如果是 $\mathrm{O}_{3}$ 首先损 害气孔调节, 那么植物对 $\mathrm{O}_{3}$ 和干旱胁迫的抗性将减 弱; 如果干旱先于 $\mathrm{O}_{3}$ 发生, 则可能通过调节气孔关 闭而使植物免受 $\mathrm{O}_{3}$ 伤害。然而干旱的这种保护作用 也可能因叶片的气孔关闭阻碍 $\mathrm{CO}_{2}$ 固定而受到限制, 最终严重影响整株植物的生长。

\section{2 植物光合碳代谢响应机制}

光合碳代谢中二磷酸核酮糖羧化酶(Rubisco)是 $\mathrm{C}_{3}$ 植物碳固定的关键酶, 同时也是植物光呼吸的关 键酶。 $\mathrm{O}_{3}$ 通过降低Rubisco酶活性、酶亚基丰度 (Brendley \& Pell, 1998; Pelloux et al., 2001)影响植物 的生理功能, 并导致净光合速率、最大羧化速率以 及气孔导度的降低(Guidi et al., 2001; Morgan et al., 2003; Biswas \& Jiang, 2011)。在卡尔文循环中一些 氧化还原调节酶类(如Rubisco活化酶、果糖-1,6-二 磷酸酶、景天庚酮糖-1,7-二磷酸酶和核酮糖-5-磷酸 激酶) 在 $\mathrm{O}_{3}$ 胁迫下受到抑制而导致其丰度降低 (Bohler et al., 2007, 2010, 2013), 使卡尔文循环被激 活。土壤因有效水分减少而降低光合速率也主要是 因为Rubisco活性的降低(Bota et al., 2004), 进而导 致植物的生长受限(Huang \& Fu, 2000)。Rubisco对胁 迫的响应往往因植物品种不同和环境的改变而不 同。如水分胁迫下烟草的Rubisco酶类受到抑制降低 了Rubisco活性(Parry et al., 2002), 而夏栎(Guercus robur)的 Rubisco活化酶增加导致Rubisco 降解(Sergeant et al., 2011), Pinus halepensis 的 Rubisco 和 Rubisco活化酶转录的丰度及蛋白含量则并未改变 (Pelloux et al., 2001)。在 $\mathrm{O}_{3}$ 与干旱的交互作用下, 因 两种胁迫各自对植物Rubisco 的影响不同和植物本 身生长阶段的不同, 表现出更加复杂多变的结果: 复合胁迫下杨树 $($ Populus tremula $\times$ P. alba) Rubisco 的降解是增加的, 但并不显著, 而且与干旱相比 $\mathrm{O}_{3}$ 的影响更强(Bohler et al., 2013)。 $\mathrm{O}_{3}$ 对P. halepensis Rubisco的影响在植物生长后期也可能强于干旱, $\mathrm{O}_{3}$ 胁迫下Rubisco活性降低, 但是干旱无持续的显著 作用, 使复合胁迫下Rubisco活性降低(Pelloux et al., 2001)。但也有结果显示P. halepensis的Rubisco活性 并未因 $\mathrm{O}_{3}$ 而改变, 而是因干旱显著降低, 使两种胁 迫下Rubisco活性显著降低(Gerant et al., 1996)。

光合碳代谢的磷酸烯醇丙酮酸羧化酶(PEPc)对 固定 $\mathrm{CO}_{2}$ 有重要作用(Hatch et al., 1969), 而且PEPc 活性增强可激发三羧酸循环保持氮代谢运行的补偿 
机制(Tietz \& Wild, 1991)。PEPc活性的变化不仅取 决于胁迫时间, 而且因品种变化而不同。例如有实 验证实干旱条件下踠豆(Pisum sativum)和Arachis pintoi 中的 PEPc 活性是增强的 (Sharma \& Nisha, 1993; Fedina \& Popova, 1996), 棉花(Gossypium hirsutum)中PEPc活性表现出降低的趋势(Pandey et al., 2001), 而P. halepensis 中PEPc的活性、数量和转录都 无显著改变(Fontaine et al., 2003)。在高浓度 $\mathrm{O}_{3}$ 下, 植物叶片的PEPc活性是增加的(Landolt et al., 1994; Lutz et al., 2000; Inclan et al., 2005), 但也可能随时 间改变而发生变化。Fontaine等(2003)就指出三年生 P. halepensis的PEPc活性只有在 $\mathrm{O}_{3}$ 暴露后期才是增 加的, 同时 $\mathrm{O}_{3}$ 和干早交互作用下生长后期的PEPc活 性也是增加的, 但是比单独 $\mathrm{O}_{3}$ 的影响低。也有结果 显示 $\mathrm{O}_{3}$ 和干旱复合胁迫对二年生 P. halepensis的 PEPc活性无影响(Inclan et al., 2005)。因此, PEPc的 活性因植物品种, 胁迫发生时间、持续时间以及两 种胁迫的作用强度不同而不同。

叶绿体电子传递链中, $\mathrm{O}_{3}$ 使光合系统和三磷腺 苷(ATP)酶的一些亚基显著降低(Bohler et al., 2007, 2011), 而植物对 $\mathrm{O}_{3}$ 伤害的抵御与 $\mathrm{O}_{3}$ 通量有关 (Dizengremel et al., 2008)。干旱加强植物气孔关闭, 限制了 $\mathrm{O}_{3}$ 的吸收, 使气体交换受限, 但同时也影响 了 ATP酶(Tezara et al., 1999; Flexas et al., 2002), 限 制了光合电子传递速率(Vitale et al., 2008)。 $\mathrm{O}_{3}$ 诱导 铁氧还蛋白-NADP ${ }^{+}$-氧化还原酶在胁迫初期快速增 加(Bohler et al., 2013), 这与氧化胁迫下植物的响应 一致(Dizengremel et al., 2008, 2009; Heath, 2008)。但 在长期的 $\mathrm{O}_{3}$ 胁迫下铁氧还蛋白- $\mathrm{NADP}^{+}$-氧化还原酶 会由于防御体系超负荷而降低, 一直降低的光合系 统亚基也可能是由叶绿体中ATP和 NADPH累积引 起, 导致卡尔文循环活力降低, 而这些都未在干旱 胁迫中发现。 $\mathrm{O}_{3}$ 和干旱交互作用下引起卡尔文循环 中的蛋白质含量降低, 这与 $\mathrm{O}_{3}$ 单独胁迫的结果相 似, 但影响程度较低, 并未产生显著的改变(Bohler et al., 2013)。可见, $\mathrm{O}_{3}$ 和干旱对植物光合碳代谢的影 响与品种和胁迫强度及实际的环境状况有关, 目前 尚缺乏复合胁迫下相关蛋白质组调控机理研究。

\section{3 植物抗氧化系统响应机制}

植物受到胁迫时, 细胞内部需要复杂的调控体 系, 包括活性氧(ROS)的信号传导、产生及清除来控 制其受到的毒害作用。因此, 植物进行氧化应激平
衡ROS的活性和抗氧化系统的能力至关重要。 $\mathrm{O}_{3}$ 和 干旱胁迫对植物的影响最主要是诱导氧化应激的不 同, $\mathrm{O}_{3}$ 会进入叶片内部并迅速转换为ROS, 导致氧化 胁迫(Rao et al., 2000; Ernst et al., 2012), 虽然严重的 干旱也可导致氧化胁迫(Foyer \& Noctor, 2000), 但干 旱胁迫下的植物应激更多是利用ROS作为内部产生 信号的分子(Yao et al., 2013)。因此, $\mathrm{O}_{3}$ 胁迫下ROS会 不断累积, 而在干旱胁迫下ROS 只是作为逆境胁迫的 响应因子存在于叶绿体中。双重胁迫诱导大量ROS产 生, 使许多细胞成分(如细胞液、蛋白质、碳水化合物、 核酸等)受到氧化伤害, 进而激发了与防御有关的蛋 白进行的解毒作用(Pääkkönen et al., 1998), 其中高活 性的清除氧化伤害的酶类保护了植物免受胁迫伤害 (Asada, 1997; Pasqualini et al., 2001)。

抗坏血酸-谷胱甘肽(AsA-GSH)循环通过调节 氧化还原反应防御ROS的伤害, 是植物细胞中主要 的抗氧化途径。植物会通过抗氧化物质的结合消除 ROS的毒害, 例如存在于叶绿体、细胞质、线粒体 和过氧化物酶体中的一些抗氧化物质, 如抗坏血酸 盐、谷胱甘肽、维生素a、超氧化物歧化酶(SOD)和 过氧化氢酶(CAT) 以及AsA-GSH循环途径中抗坏血 酸过氧化物酶(APX)、单脱水抗坏血酸还原酶 (MDAR)、脱氢抗坏血酸还原酶(DHAR)和谷胱甘肽 还原酶(GR)等构成细胞器中重要的抗氧化防御体 系, 防止过氧化氢 $\left(\mathrm{H}_{2} \mathrm{O}_{2}\right)$ 的产生 (Potters et al., 2002)。Iyer等(2013)证实由于还原型AsA和GSH的增 加, $\mathrm{O}_{3}$ 和干旱复合胁迫下ROS的水平与无胁迫对照 相近。干旱增加了Fagus crenata叶片的GSH含量, 提高了抗性机制, 减轻了植物受到的 $\mathrm{O}_{3}$ 伤害(Watanabe et al., 2005)。O $\mathrm{O}_{3}$ 暴露下植物的APX、CAT、SOD 等抗氧化酶类的活性和(或)丰度是增加的(Alonso et $a l ., 2001)$, 且干旱条件下植物的GR和SOD也是增加 的(Alonso et al., 2001; Huseynova et al., 2014), 而与 $\mathrm{O}_{3}$ 和干旱的单独胁迫相比, 两者交互作用下抗氧化 酶类反而是降低的, 从而推断两种胁迫的累积作用 破坏了植物的防御体系 (Wellburn et al., 1996; Alonso et al., 2001)。因此, 植物对 $\mathrm{O}_{3}$ 与干旱的去氧 化响应取决于两种胁迫诱导产生的抗氧化分子和酶 类的多少。但目前仍缺乏转录水平与AsA-GSH循环 中基因调控的蛋白酶活性的相关性研究(Creissen \& Mullineaux, 2002; Iyer et al., 2013)。

AsA 是AsA-GSH循环中一种主要的抗氧化剂, 
直接与羟基自由基、超氧化物和单线态氧反应, 在 光合作用调节中也起重要作用(Noctor \& Foyer, 1998), 并作为电子供体将 $\mathrm{H}_{2} \mathrm{O}_{2}$ 还原为水, 而 AsA的 生成需要NADPH的还原力, 同时Rubisco活性降低, PEPC活性升高。质外体系统(质外体AsA和 APX) 是 对氧化伤害的第一层防御体系(Luwe et al., 1993; Sanmartin et al., 2003)。植物对 $\mathrm{O}_{3}$ 的敏感性也与叶片 组织AsA的氧化还原态有关(Conklin \& Barth, 2004; Chen \& Gallie, 2005)。另外, AsA也是植物细胞质、 叶绿体、液泡、线粒体和质外体中主要的氧化还原 缓冲剂(Potters et al., 2002; Pignocchi et al., 2003)。总 AsA水平降低了由ROS对细胞造成的伤害程度, 与 植物的耐早性有重要关系, 而DHAR的活性增加与 干旱胁迫的程度也有关(Sofo et al., 2005)。干旱条件 下, 细胞质和叶绿体中的AsA发挥重要的解毒作用, 且主要取决于植物的种类(Mittler \& Zilinskas, 1994; Zhang \& Kirkham, 1996)。欧洲云杉(Picea abies)针 叶中总AsA含量因 $\mathrm{O}_{3}$ 胁迫而增加, 同时干旱胁迫使 其质外体AsA也显著增加, 且在共同胁迫下两者都 是显著增加的(Kronfuß et al., 1998)。因此, $\mathrm{O}_{3}$ 和干旱 复合胁迫可能增加了还原力, 同时促进了氧化胁迫 下植物的防护作用。

抗氧化系统在植物对 $\mathrm{O}_{3}$ 和干旱胁迫的抗性中 发挥重要的作用, $\mathrm{O}_{3}$ 增加了抗氧化物的浓度和抗氧 化酶的活性(Alonso et al., 2001; Herbinger et al., 2005)且增强了抗氧化系统相关的基因表达(Gupta et al., 2005)。虽然AsA含量与植物的抗性密切相关, 如烟草中DHAR过量表达也证实了增加的AsA含量 增强了其对 $\mathrm{O}_{3}$ 和干旱的抗性(Chen \& Gallie, 2005; Eltayeb et al., 2006), 但也有研究指出两种白车轴草 (Trifolium repens)质外体中的AsA含量差异无法说 明 $\mathrm{O}_{3}$ 的抗性差异(D’Haese et al., 2005)。干旱胁迫也 增加了植物叶片抗氧化物质的浓度或改变其氧化还 原态(Šircelj et al., 2005; Talbi et al., 2015)。然而当干 旱达到一定程度时, 抗氧化物的活性却降低, 从而 使植物受到伤害(Quartacci \& Navari-Izzo, 1992; Zhang \& Kirkham 1994; Alonso et al., 2001)。因此, $\mathrm{O}_{3}$ 和干旱胁迫下植物的抗氧化响应是多变的, 因植 物品种、胁迫时间及胁迫强度各异, 其内在的作用 机制也需进一步明确。

\section{4 植物的生长响应}

$\mathrm{O}_{3}$ 和干旱对不同植物的器官、组织和细胞具有
不同程度的氧化伤害, 当胁迫达到一定程度时, 首 先伤害敏感植物的叶片, 进而限制整株植物的生 长。两种胁迫下叶片的表观伤害症状则各有特征。 $\mathrm{O}_{3}$ 引起叶片坏疽斑块和不规则的裉绿、萎黄斑点, 而干旱引起叶片同质和渐进的变色, 同时伴有叶片 的发育不良和卷曲下垂(Bohler et al., 2013)。 $\mathrm{O}_{3}$ 和干 旱交互作用下的植物则并不表现为一致的加重伤 害。与单独胁迫下的植物相比, 双重胁迫可能减弱 (Showman, 1991; Iyer et al., 2013)或者加重(Bohler et al., 2013)叶片受伤害的表型特征。因此, 叶片的 不同伤害症状表现可能是由于病斑的产生与胁迫诱 导ROS大量生成并引发植物自身调节抗氧化系统有 关, 不一定是气孔吸收 $\mathrm{O}_{3}$ 所致(Grulke et al., 2003a)。 这也表明 $\mathrm{O}_{3}$ 和干旱的相互作用对植物的影响在表 观上和形态学上可能是相似的或累积的。但即使 $\mathrm{O}_{3}$ 和(或)干旱胁迫下植物未表现出明显可见的叶片伤 害症状, 其生长最后也可能受到限制(Shimizu \& Feng, 2007)。

$\mathrm{O}_{3}$ 和干旱都会引起光合速率的降低并由此影 响净 $\mathrm{CO}_{2}$ 的固定(Flexas et al., 2002; Wittig et al., 2007; Biswas \& Jiang, 2011), 而在 $\mathrm{O}_{3}$ 胁迫之后发生 的干旱加重了对植物净同化率和光合效率的伤害 (Grulke et al., 2002), 导致生物量降低。生物量的降 低包括种子质量和数量的降低(Flexas et al., 2002; Biswas \& Jiang, 2011), 且 $\mathrm{O}_{3}$ 和干旱同时发生对植物 生物量降低是累积效应(Biswas \& Jiang, 2011)。不同 的植物对胁迫的响应是不同的, 且干旱对植物的影 响可能更大。水分胁迫对夏柇的伤害影响并不明显, 对欧洲山毛榉甚至没有影响, 但降低了杨树(Populus maximowiczii $\times$ P. berolinensis $)$ 的生长, 包括茎 粗和生物量, 而且 $\mathrm{O}_{3}$ 和干旱的交互作用加剧了对杨 树叶绿素苂光参数和生长的伤害(Pollastrini et al., 2010)。即使高浓度 $\mathrm{O}_{3}$ 促进土壤呼吸, 增加了细根的 生长, 但是在干旱胁迫下欧洲云杉根系的生长仍然 受到限制, 而山毛榉却未有此现象, 可能对云杉而 言干旱更占主导地位(Nikolova et al., 2010)。在德国 克兰茨贝格的森林实验点也证实干旱的影响可能更 大。 $\mathrm{O}_{3}$ 对山毛榉树的影响也因水分亏缺而大大降低, 对茎粗和整个茎杆体积增量的有害影响很大程度上 是因干旱造成的(Matyssek et al., 2010)。

综上所述, $\mathrm{O}_{3}$ 和干旱的交互作用不仅依赖于植 物本身和外部环境因素, 而且依赖于两种胁迫的强 
度以及发生的先后次序。尽管干旱诱导的气孔导度 降低限制了 $\mathrm{O}_{3}$ 的吸收, 但 $\mathrm{O}_{3}$ 被视作是一种附加的胁 迫, 改变了植物的生理, 增加了氧化胁迫, 引起抗 氧化物的累积(Alonso et al., 2001), 从而植物更易 受到其他环境胁迫(如干旱、病虫害、升温等)的伤 害。而且, 即使干旱初期可以保护植物抵御 $\mathrm{O}_{3}$ 伤害, 但是这种保护作用也只限于短期内的叶片水平, 长 期的气孔关闭必将影响碳同化, 导致生物量降低。 由于干旱直接作用于植物的根部, 影响到同化物的 运输和分配, 而 $\mathrm{O}_{3}$ 攻击的直接位点是植物的叶片, 因此可能导致干旱对植物的伤害比 $\mathrm{O}_{3}$ 对植物的伤 害更严重。同时，持续的土壤水分亏缺也使植物更 易受到其他胁迫(如风、生物危害)的伤害, 而长期的 $\mathrm{O}_{3}$ 胁迫也使树木更易受到干旱的伤害(Matyssek et al., 2006)。

\section{2 总结和展望}

近地层 $\mathrm{O}_{3}$ 浓度升高和干旱这两种胁迫在自然 界中是相随发生的。其复合作用常常引起累积效应。 干旱引起的气孔关闭或许可以减少植物对 $\mathrm{O}_{3}$ 的吸 收, 并由此降低 $\mathrm{O}_{3}$ 的毒害作用。然而在水分胁迫期 气孔关闭的保护作用也可能会受到 $\mathrm{O}_{3}$ 干扰, 加重植 物的伤害程度。因此两种胁迫的复合影响是由多种 因素共同决定的。

$\mathrm{O}_{3}$ 和干旱交互作用因胁迫发生的先后次序而 不同, 植物对 $\mathrm{O}_{3}$ 的累积暴露阈值可归因于不同阶段 生理的改变或是干旱发生的时间。 $\mathrm{O}_{3}$ 胁迫先于干旱 发生时, 气孔的延迟关闭加重干旱条件下的水分损 失, 使 $\mathrm{O}_{3}$ 能持续毒害植物。反之, 干旱胁迫先于 $\mathrm{O}_{3}$ 发生时, 干旱引起的气孔关闭形成最首要的自然屏 障, 抵御了 $\mathrm{O}_{3}$ 的进入。如常年生长在干旱环境中的 地中海常绿植物可能延续了它们逐渐产生的内在的 $\mathrm{O}_{3}$ 抗性(Nali et al., 2004)。当植物在 $\mathrm{O}_{3}$ 胁迫之前就曾 有过其他胁迫时, 植物在适应环境变化时附加了额 外的负担, $\mathrm{O}_{3}$ 的伤害是累加的, 对植物造成不可逆 的永久伤害。总之, 不管是单独的胁迫还是两者结 合, 都会因品种、 $\mathrm{O}_{3}$ 通量、抗氧化能力、敏感性、 发生时间、生长期等不同引起植物对 $\mathrm{O}_{3}$ 和干旱的响 应差异。

目前的文献报道 $\mathrm{O}_{3}$ 和干旱交互作用对植物的 影响研究大多局限在光合、生理及生长指标等中观 尺度上, 但不同的研究方法和对象对于两种胁迫因
子的交互作用对植物内在机制的影响方面尚无明确 结论。因此, 未来的研究需要运用一些先进的分子 生物学技术和手段更加系统深入地研究光合碳代谢 过程中蛋白相互作用的调节及抗氧化内在机制, 识 别单因子胁迫与复合胁迫对植物生长的影响。同时 包含更多的研究区域, 更全面的物种响应, 更集中 的全球变化下多因子胁迫对植物抗性机制的研究, 以便获得更加接近真实环境的实验结果。同时延长 实验研究的时间, 以便于更加明确植物对胁迫的短 期和长期响应。生物信息学方法和高通量技术(如转 录组学、蛋白质组学和代谢组学等)的应用可更加直 观地阐释两种胁迫下植物的内在响应机制。将此类 高新技术应用到室内高频率模拟和大田长周期接近 自然的实验, 对于进一步了解复合胁迫对植物生长 的影响将会有更深的突破。由此, 在明确 $\mathrm{O}_{3}$ 和干旱 胁迫下植物的响应机理基础上，通过基因工程改进 不同植物品种抗氧化胁迫酶类的表达, 进而增强植 物的抗性, 以适应未来的多变气候。

自然界的植物是多样性的, 面对的胁迫是多重 的, 但实验研究往往无法囊括不同品种、不同生长 阶段以及多重胁迫的影响。最终的实验结果了解到 的仅是局限于某一物种、某一生长期(幼树或成熟大 树)对某一特定胁迫的响应。未来的研究方向是将个 体的响应扩展至生态系统的尺度, 并整合各种环境 因素下的实验结果进行meta分析, 在充分考虑到各 种环境因素的交互作用对生态系统组成和功能影响 的基础上, 建立更加完善的生态系统模型, 降低未 来预测全球陆地生态系统碳、氮、水和养分循环变 化时的不确定性。同时, 在模型模拟基础上分析并 确立不确定性的关键区域, 进行多变量预测植物的 气孔响应, 并在长期的田间实验基础上, 评价植物 在复杂自然环境下的生长, 进而准确模拟气孔对 $\mathrm{O}_{3}$ 和干旱的响应, 这对于研究 $\mathrm{O}_{3}$ 和干旱复合胁迫环境 下植物对水分利用的影响至关重要。

未来的研究需要将自然环境中的多因素胁迫结 合, 集成多因子交互作用的区域模型, 并使用分子 生物学的研究方法和技术手段对植物进行更微观的 研究集成, 从而全面地揭示植物对多因子环境胁迫 的响应, 并进行抗性品种的培育和改进风险评估。

基金项目 中国科学院“百人计划”项目和国家自然 科学基金(31500396)。 


\section{参考文献}

Abrams MD, Kubiske ME, Mostoller SA (1994). Relating wet and dry year ecophysiology to leaf structure in contrastingtemperate tree species. Ecology, 75, 123-133.

Alonso R, Elvira S, Castillo FJ, Gimeno BS (2001). Interactive effects of ozone and drought stress on pigments and activities of antioxidative enzymes in Pinus halepensis. Plant, Cell \& Environment, 24, 905-916.

Alonso R, Elvira S, González-Fernández I, Calvete H, GarcíaGómez H, Bermejo V (2014). Drought stress does not protect Quercus ilex L. from ozone effects: Results from a comparative study of two subspecies differing in ozone sensitivity. Plant Biology, 16, 375-384.

Anjum F, Yaseen M, Rasul E, Wahid A, Anjum S (2003). Water stress in barley (Hordeum vulgare L.). II. Effect on chemical composition and chlorophyll contents. Pakistan Journal of Agricultural Sciences, 40(1-2), 45-49.

Asada K (1997). The role of ascorbate peroxidase and monodehydroascorbate reductase in $\mathrm{H}_{2} \mathrm{O}_{2}$ scavenging in plants. Oxidatives Stress and the Molecular Biology of Antioxidant Defenses, 34, 715-735.

Ashmore MR (2005). Assessing the future global impacts of ozone on vegetation. Plant, Cell \& Environment, 28, 949-964.

Avnery S, Mauzerall DL, Liu JF, Horowitz LW (2011). Global crop yield reductions due to surface ozone exposure: 2 . Year 2030 potential crop production losses and economic damage under two scenarios of $\mathrm{O}_{3}$ pollution. Atmospheric Environment, 45, 2297-2309.

Biehler K, Fock H (1996). Evidence for the contribution of the Mehler-peroxidase reaction in dissipating excess electrons in drought-stressed wheat. Plant Physiology, 112, 265272.

Biswas DK, Jiang GM (2011). Differential drought-induced modulation of ozone tolerance in winter wheat species. Journal of Experimental Botany, 62, 4153-4162.

Bohler S, Bagard M, Oufir M, Planchon S, Hoffmann L, Jolivet Y, Hausman J-F, Dizengremel P, Renaut J (2007). A DIGE analysis of developing poplar leaves subjected to ozone reveals major changes in carbon metabolism. Proteomics, 7, 1584-1599.

Bohler S, Sergeant K, Hoffmann L, Dizengremel P, Hausman J-F, Renaut J, Jolivet Y (2011). A difference gel electrophoresis study on thylakoids isolated from poplar leaves reveals a negative impact of ozone exposure on membrane proteins. Journal of Proteome Research, 10, 3003-3011.

Bohler S, Sergeant K, Jolivet Y, Hoffmann L, Hausman J-F, Dizengremel P, Renaut J (2013). A physiological and proteomic study of poplar leaves during ozone exposure combined with mild drought. Proteomics, 13, 1737-1754.

Bohler S, Sergeant K, Lefevre I, Jolivet Y, Hoffmann L, Renaut J, Dizengremel P, Hausman J-F (2010). Differential im- pact of chronic ozone exposure on expanding and fully expanded poplar leaves. Tree Physiology, 30, 1415-1432.

Bota J, Medrano H, Flexas J (2004). Is photosynthesis limited by decreased Rubisco activity and RuBP content under progressive water stress? New phytologist, 162, 671-681.

Bréda N, Huc R, Granier A, Dreyer E (2006). Temperate forest trees and stands under severe drought: A review of ecophysiological responses, adaptation processes and longterm consequences. Annals of Forest Science, 63, 625644.

Brendley BW, Pell EJ (1998). Ozone-induced changes in biosynthesis of Rubisco and associated compensation to stress in foliage of hybrid poplar. Tree Physiology, 18, 81-90.

Broadmeadow M (1998). Ozone and forest trees. New Phytologist, 139, 123-125.

Buckland SM, Price AH, Hendry GAF (1991). The role of ascorbate in drought-treated Cochlearia atlantica Pobed. and Armeria maritima (Mill.) Willd. New Phytologist, 119, 155-160.

Chang SC, Lee CT (2006). Ozone variations through vehicle emissions reductions based on air quality monitoring data in Taipei City, Taiwan, from 1994 to 2003. Atmospheric Environment, 40, 3513-3526.

Chen Z, Gallie DR (2005). Increasing tolerance to ozone by elevating foliar ascorbic acid confers greater protection against ozone than increasing avoidance. Plant Physiology, 138, 1673-1689.

Ciais P, Reichstein M, Viovy N, Granier A, Ogee J, Allard V, Aubinet M, Buchmann N, Bernhofer C, Carrara A, Chevallier F, de Noblet N, Friend AD, Friedlingstein P, Grunwald T, Heinesch B, Keronen P, Knohl A, Krinner G, Loustau D, Manca G, Matteucci G, Miglietta F, Ourcival JM, Papale D, Pilegaard K, Rambal S, Seufert G, Soussana JF, Sanz MJ, Schulze ED, Vesala T, Valentini R (2005). Europe-wide reduction in primary productivity caused by the heat and drought in 2003. Nature, 437, 529-533.

Comte DL (1998). Weather highlights around the world. Weatherwise, 51(2), 26-31.

Conklin PL, Barth C (2004). Ascorbic acid, a familiar small molecule intertwined in the response of plants to ozone, pathogens, and the onset of senescence. Plant, Cell \& Environment, 27, 959-970.

Cowan IR (1978). Stomatal behaviour and environment. Advances Botanical Research, 4, 117-228.

Creissen GP, Mullineaux PM (2002). The molecular biology of the ascorbate-glutathione cycle in higher plants. In: Inzé D, Montagu MV eds. Oxidative Stress in Plants. Taylor \& Francis, Abingdon, UK. 247-270.

Dai A (2011). Drought under global warming: A review. Climate Change, 2(1), 45-65.

Desotgiu R, Pollastrini M, Cascio C, Gerosa G, Marzuoli R, Bussotti F (2012). Chlorophyll a fluorescence analysis 
along a vertical gradient of the crown in a poplar (Oxford clone) subjected to ozone and water stress. Tree Physiology, 32, 976-986.

D’Haese D, Vandermeiren K, Asard H, Horemans N (2005). Other factors than apoplastic ascorbate contribute to the differential ozone tolerance of two clones of Trifolium repens L. Plant, Cell \& Environment, 28, 623-632.

Dizengremel P (2001). Effects of ozone on the carbon metabolism of forest trees. Plant Physiology and Biochemistry, 39, 729-742.

Dizengremel P, Jolivet Y, Tuzet A, Ranieri A, Le Thiec D (2013). Integrative leaf-level phytotoxic ozone dose assessment for forest risk modelling. Developments in Environmental Science, 13, 267-288.

Dizengremel P, Le Thiec D, Bagard M, Jolivet Y (2008). Ozone risk assessment for plants: Central role of metabolism-dependent changes in reducing power. Environmental Pollution, 156, 11-15.

Dizengremel P, Le Thiec D, Hasenfratz-Sauder MP, Vaultier MN, Bagard M, Jolivet Y (2009). Metabolic-dependent changes in plant cell redox power after ozone exposure. Plant Biology, 11 (Suppl. 1), 35-42.

Dumont J, Spicher F, Montpied P, Dizengremel P, Jolivet Y, Le Thiec D (2013). Effects of ozone on stomatal responses to environmental parameters (blue light, red light, $\mathrm{CO}_{2}$ and vapour pressure deficit) in three Populus deltoides $\times$ Populus nigra genotypes. Environmental Pollution, 173, 85-96.

Edwards IP, Zak DR (2011). Fungal community composition and function after long-term exposure of northern forests to elevated atmospheric $\mathrm{CO}_{2}$ and tropospheric $\mathrm{O}_{3}$. Global Change Biology, 17, 2184-2195.

Eltayeb AE, Kawano N, Badawi GH, Kaminaka H, Sanekata T, Morishima I, Shibahara T, Inanaga S, Tanaka K (2006). Enhanced tolerance to ozone and drought stresses in transgenic tobacco overexpressing dehydroascorbate reductase in cytosol. Physiologia Plantarum, 127, 57-65.

Ernst D, Jürgensen M, Bahnweg G, Heller W, Müller-Starck G (2012). Common links of molecular biology with biochemistry and physiology in plants under ozone and pathogen attack. In: Matyssek R, Schnyder H, Oßwald W, Ernst D, Munch CJ, Pretzsch H eds. Growth and Defence in Plants: Resource Allocation at Multiple Scales. Springer, Berlin. 29-51.

Fedina IS, Popova AV (1996). Photosynthesis, photorespiration and proline accumulation in water-stressed pea leaves. Photosynthetica, 32, 213-220.

Feng YW, Shimizu H (2005). Effects of ozone and/or water stress on the growth of Abies veitchii seedlings. PhytonAnnales Rei Botanicae, 45, 591-594.

Feng ZZ, Sun JS, Wan WX, Hu EZ, Calatayud V (2014). Evidence of widespread ozone-induced visible injury on plants in Beijing, China. Environmental Pollution, 193, 296-301.

Feng ZZ, Kobayashi K (2009). Assessing the impacts of current and future concentrations of surface ozone on crop yield with meta-analysis. Atmospheric Environment, 43, 1510 1519.

Flexas J, Bota J, Escalona JM, Sampol B, Medrano H (2002). Effects of drought on photosynthesis in grapevines under field conditions: An evaluation of stomatal and mesophyll limitations. Functional Plant Biology, 29, 461-471.

Fontaine V, Cabane M, Dizengremel P (2003). Regulation of phosphoenolpyruvate carboxylase in Pinus halepensis needles submitted to ozone and water stress. Physiologia Plantarum, 117, 445-452.

Foyer CH, Noctor G (2000). Oxygen processing in photosynthesis: Regulation and signalling. New Phytologist, 146, 359-388.

Fu JM, Huang BR (2001). Involvement of antioxidants and lipid peroxidation in the adaptation of two cool-season grasses to localized drought stress. Environmental and Experimental Botany, 45, 105-114.

Gerant D, Podor M, Grieu P, Afif D, Cornu S, Morabito D, Banvoy J, Robin C, Dizengremel P (1996). Carbon metabolism enzyme activities and carbon partitioning in Pinus halepensis Mill. exposed to mild drought and ozone. Journal of Plant Physiology, 148, 142-147.

Grulke NE, Johnson R, Esperanza A, Jones D, Nguyen T, Posch S, Tausz M (2003a). Canopy transpiration of Jeffrey pine in mesic and xeric microsites: $\mathrm{O}_{3}$ uptake and injury response. Trees, 17, 292-298.

Grulke NE, Johnson R, Monschein S, Nikolova P, Tausz M (2003b). Variation in morphological and biochemical $\mathrm{O}_{3}$ injury attributes of mature Jeffrey pine within canopies and between microsites. Tree Physiology, 23, 923-929.

Grulke NE, Preisler HK, Rose C, Kirsch J, Balduman L (2002). $\mathrm{O}_{3}$ uptake and drought stress effects on carbon acquisition of ponderosa pine in natural stands. New Phytologist, 154, 621-631.

Grünhage L, Jager HJ (2003). From critical levels to critical loads for ozone: A discussion of a new experimental and modelling approach for establishing flux-response relationships for agricultural crops and native plant species. Environmental Pollution, 125, 99-110.

Guidi L, Nali C, Lorenzini G, Filippi F, Soldatini GF (2001). Effect of chronic ozone fumigation on the photosynthetic process of poplar clones showing different sensitivity. Environmental Pollution, 113, 245-254.

Gupta P, Duplessis S, White H, Karnosky DF, Martin F, Podila GK (2005). Gene expression patterns of trembling aspen trees following long-term exposure to interacting elevated $\mathrm{CO}_{2}$ and tropospheric $\mathrm{O}_{3}$. New Phytologist, 167, 129-142.

Haberer K, Herbinger K, Alexou M, Rennenberg H, Tausz M

www.plant-ecology.com 
(2008). Effects of drought and canopy ozone exposure on antioxidants in fine roots of mature European beech (Fagus sylvatica). Tree Physiology, 28, 713-719.

Hao YT, Lin M, Xue L, Wang ZY, Lin JT, Liang ZY, Sun BC, Tian MT (2014). Effects of ozone stress and drought stress on photosynthesis characteristics of Syzygium hainanense and Alstonia scholaris seedlings. Journal of Anhui Agricultural University, 41, 193-197. (in Chinese with English abstract) [郝云亭, 林敏, 薛立, 王志云, 林婧庭, 梁梓 毅, 孙冰超, 田茂涛 (2014). 臭氧与干旱胁迫对海南蒲 桃和盆架子幼苗光合生理的影响. 安徽农业大学学报, 41, 193-197.]

Hatch M, Slack C, Bull T (1969). Light-induced changes in the content of some enzymes of the $\mathrm{C}_{4}$-dicarboxylic acid pathway of photosynthesis and its effect on other characteristics of photosynthesis. Phytochemistry, 8, 697-706.

Heath RL (1994). Alterations of plant metabolism by ozone exposure. In: Alscher RG, Wellburn AR eds. Plant Responses to the Gaseous Environment: Molecular, Metabolic and Physiological aspects. Springer Netherlands, Dordrecht. 121-145.

Heath RL (2008). Modification of the biochemical pathways of plants induced by ozone: What are the varied routes to change? Environmental Pollution, 155, 453-463.

Heath RL, Taylor GE (1997). Physiological processes and plant responses to ozone exposure. In: Sandermann $\mathrm{H}$, Wellburn AR, Heath RL eds. Forest Decline and Ozone: A Comparison of Controlled Chamber and Field Experiments. Springer, Berlin. 317-368.

Heber U, Kaiser W, Luwe M, Kindermann G, VeljovicJavonovic S, Yin Z, Pfanz H, Slovik S (1995). Air pollution, photosynthesis and forest decline: Interactions and consequences. In: Schulze E-D, Caldwell MM eds. Ecophysiology of Photosynthesis. Springer, Berlin. 279-296.

Herbinger K, Tausz M, Wonisch A, Soja G, Sorger A, Grill D (2002). Complex interactive effects of drought and ozone stress on the antioxidant defence systems of two wheat cultivars. Plant Physiology and Biochemistry, 40, 691696.

Herbinger K, Then C, Low M, Haberer K, Alexous M, Koch N, Remele K, Heerdt C, Grill D, Rennenberg H, Haberle KH, Matyssek R, Tausz M, Wieser G (2005). Tree age dependence and within-canopy variation of leaf gas exchange and antioxidative defence in Fagus sylvatica under experimental free-air ozone exposure. Environmental Pollution, 137, 476-482.

Hoshika Y, Carriero G, Feng ZZ, Zhang YL, Paoletti E (2014). Determinants of stomatal sluggishness in ozone-exposed deciduous tree species. Science of the Total Environment, 481, 453-458.

Hoshika Y, Omasa K, Paoletti E (2013). Both ozone exposure and soil water stress are able to induce stomatal sluggish- ness. Environmental and Experimental Botany, 88, 19-23.

Hoshika Y, Watanabe M, Inada N, Koike $T$ (2012). Ozone-induced stomatal sluggishness develops progressively in Siebold's beech (Fagus crenata). Environmental Pollution, 166, 152-156.

Huang BR, Fu JM (2000). Photosynthesis, respiration, and carbon allocation of two cool-season perennial grasses in response to surface soil drying. Plant and Soil, 227(1-2), $17-26$.

Huseynova IM, Aliyeva DR, Aliyev JA (2014). Subcellular localization and responses of superoxide dismutase isoforms in local wheat varieties subjected to continuous soil drought. Plant Physiology and Biochemistry, 81, 54-60.

ICP Vegetation (2011). Ozone pollution: A hidden threat to food security. Programme Coordination Centre for the ICP Vegetation. In: Mills G, Harmens H eds. Programme Coordination Centre for the ICP Vegetation. NERC/Centre for Ecology and Hydrology, Bangor, UK. 116.

Inclan R, Gimeno BS, Dizengremel P, Sanchez M (2005). Compensation processes of Aleppo pine (Pinus halepensis Mill.) to ozone exposure and drought stress. Environmental Pollution, 137, 517-524.

IPCC (Intergovernmental Panel on Climate Change) (2013). Climate Change 2013: The Physical Science Basis. Working Group I Contribution to the Fifth Assessment Report of the Intergovernmental Panel on Climate Change. Cambridge University Press, Cambridge, UK and New York, USA. 1552.

Iyer NJ, Tang Y, Mahalingam R (2013). Physiological, biochemical and molecular responses to a combination of drought and ozone in Medicago truncatula. Plant, Cell \& Environment, 36, 706-720.

Karlsson PE, Medin EL, Wickstrom H, Sellden G, Wallin G, Ottosson S, Skarby L (1995). Ozone and drought stressInteractive effects on the growth and physiology of Norway spruce (Picea abies (L) Karst). Water, Air, \& Soil Pollution, 85, 1325-1330.

Karlsson PE, Pleijel H, Karlsson GP, Medin EL, Skarby L (2000). Simulations of stomatal conductance and ozone uptake to Norway spruce saplings in open-top chambers. Environmental Pollution, 109, 443-451.

Karnosky DF, Pregitzer KS, Zak DR, Kubiske ME, Hendrey GR, Weinstein D, Nosal M, Percy KE (2005). Scaling ozone responses of forest trees to the ecosystem level in a changing climate. Plant, Cell \& Environment, 28, 965981.

Karnosky DF, Werner H, Holopainen T, Percy K, Oksanen T, Oksanen E, Heerdt C, Fabian P, Nagy J, Heilman W, Cox R, Nelson N, Matyssek R (2007). Free-air exposure systems to scale up ozone research to mature trees. Plant Biology, 9, 181-190.

Kaya MD, Okcu G, Atak M, Cikili Y, Kolsarici O (2006). Seed 
treatments to overcome salt and drought stress during germination in sunflower (Helianthus annuus L.). European Journal of Agronomy, 24, 291-295.

Khan S, Soja G (2003). Yield responses of wheat to ozone exposure as modified by drought-induced differences in ozone uptake. Water, Air, \& Soil Pollution, 147, 299-315.

Kivimäenpää M, Sutinen S, Karlsson PE, Sellden G (2003). Cell structural changes in the needles of Norway spruce exposed to long-term ozone and drought. Annals of Botany, 92, 779-793.

Kivimäenpää M, Sutinen S, Medin EL, Karlsson PE, Sellden G (2001). Diurnal changes in microscopic structures of mesophyll cells of Norway spruce, Picea abies (L.) Karst., and the effects of ozone and drought. Annals of Botany, 88, 119-130.

Kou TJ, Chang HQ, Zhang LH, Xu XF, Guo DY, Zhou WL, Zhu JG, Miao YF (2009). Effects of ground-level $\mathrm{O}_{3}$ pollution on the terrestrial ecosystem. Ecology and Environmental Sciences, 18, 704-710. (in Chinese with English abstract) [寇太记, 常会庆, 张联合, 徐晓峰, 郭大勇, 周文利, 朱建国, 苗艳芳 (2009). 近地层 $\mathrm{O}_{3}$ 污染对陆地 生态系统的影响. 生态环境学报, 18, 704-710.]

Kronfuß G, Polle A, Tausz M, Havranek WM, Wieser G (1998). Effects of ozone and mild drought stress on gas exchange, antioxidants and chloroplast pigments in current-year needles of young Norway spruce [Picea abies (L.) Karst]. Trees, 12, 482-489.

Kuehn AR, Grill S, Baumgarten M, Ankerst DP, Matyssek R (2015). Daily growth of European beech (Fagus sylvatica L.) on moist sites is affected by short-term drought rather than ozone uptake. Trees, 29, 1501-1519.

Landolt W, Günthardt-Goerg M, Pfenninger I, Scheidegger C (1994). Ozone induced microscopical changes and quantitative carbohydrate contents of hybrid poplar (Populus $\times$ euramericana). Trees, 8, 183-190.

Le Thiec D, Dixon M, Garrec JP (1994). The effects of slightly elevated ozone concentrations and mild drought stress on the physiology and growth of Norway Spruce, Picea abies (L.) Karst. and beech, Fagus sylvatica L., in open-top chambers. New Phytologist, 128, 671-678.

Li L, Chen CH, Huang C, Huang HY, Zhang GF, Wang YJ, Chen MH, Wang HL, Chen YR, Streets DG, Fu JM (2011). Ozone sensitivity analysis with the MM5-CMAQ modeling system for Shanghai. Journal of Environmental Sciences, 23, 1150-1157.

Li L, Manning WJ, Tong L, Wang XK (2015). Chronic drought stress reduced but not protected Shantung maple (Acer truncatum Bunge) from adverse effects of ozone $\left(\mathrm{O}_{3}\right)$ on growth and physiology in the suburb of Beijing, China. Environmental Pollution, 201, 34-41.

Li QJ, Lu GC, Xue L, Tian MT, Lin M, Lin JT (2015). Effects of ozone and drought on fluorescence physiology of seed- lings of three afforestation tree species in South China. Journal of South China Agricultural University, 36, 91-95. (in Chinese with English abstract) [李秋静, 卢广 超, 薛立, 田茂涛, 林敏, 林婧庭 (2011). 臭氧与干旱 胁迫对华南地区3种绿化树种. 华南农业大学学报, 36, 91-95.]

Löw M, Herbinger K, Nunn AJ, Haeberle KH, Leuchner M, Heerdt C, Werner H, Wipfler P, Pretzsch H, Tausz M, Matyssek R (2006). Extraordinary drought of 2003 overrules ozone impact on adult beech trees (Fagus sylvatica). Trees, 20, 539-548.

Lutz C, Anegg S, Gerant D, Alaoui-Sosse B, Gerard J, Dizengremel P (2000). Beech trees exposed to high $\mathrm{CO}_{2}$ and to simulated summer ozone levels: Effects on photosynthesis, chloroplast components and leaf enzyme activity. Physiologia Plantarum, 109, 252-259.

Luwe MWF, Takahama U, Heber U (1993). Role of ascorbate in detoxifying ozone in the apoplast of spinach (Spinacia oleracea L.) leaves. Plant Physiology, 101, 969-976.

Maier-Maercker U (1998). Image analysis of the stomatal cell walls of Picea abies (L.) Karst. in pure and ozone-enriched air. Trees, 12, 181-185.

Manderscheid R, Jäger H-J, Schoeneberger M (1991). Doseresponse relationships of ozone effects on foliar levels of antioxidants, soluble polyamines and peroxidase activity of Pinus taeda (L.): Assessment of the usefulness as early ozone indicators. Angewandte Botanik, 29, 188.

Manes F, Donato E, Vitale M (2001). Physiological response of Pinus halepensis needles under ozone and water stress conditions. Physiologia Plantarum, 113, 249-257.

Matyssek R, Innes JL (1999). Ozone-A risk factor for trees and forests in Europe? Water, Air, \& Soil Pollution, 116, 199-226.

Matyssek R, Kozovits AR, Schnitzler J-P, Pretzsch H, Dieler J, Wieser G (2014). Forest trees under air pollution as a factor of climate change. In: Tausz M, Grulke N eds. Trees in a Changing Environment: Ecophysiology, Adaptation, and Future Survival. Springer, Dordrecht, The Netherlands. 117-163.

Matyssek R, Le Thiec D, Löw M, Dizengremel P, Nunn AJ, Häberle $\mathrm{KH}$ (2006). Interactions between drought and $\mathrm{O}_{3}$ stress in forest trees. Plant Biology, 8, 11-17.

Matyssek R, Sandermann H (2003). Impact of ozone on trees: An ecophysiological perspective. Progress in Botany, 64, 349-404.

Matyssek R, Wieser G, Calfapietra C, de Vries W, Dizengremel P, Ernst D, Jolivet Y, Mikkelsen TN, Mohren GMJ, Le Thiec D, Tuovinen JP, Weatherall A, Paoletti E (2012). Forests under climate change and air pollution: Gaps in understanding and future directions for research. Environmental Pollution, 160, 57-65.

Matyssek R, Wieser G, Ceulemans R, Rennenberg H, Pretzsch

www.plant-ecology.com 
H, Haberer K, Loew M, Nunn AJ, Werner H, Wipfler P, Osswaldg W, Nikolova P, Hanke DE, Kraigher H, Tausz M, Bahnweg G, Kitao M, Dieler J, Sandermann H, Herbinger $\mathrm{K}$, Grebenc $\mathrm{T}$, Blumenroether $\mathrm{M}$, Deckmyn $\mathrm{G}$, Grams TEE, Heerdt C, Leuchner M, Fabian P, Haeberle KH (2010). Enhanced ozone strongly reduces carbon sink strength of adult beech (Fagus sylvatica)—Resume from the free-air fumigation study at Kranzberg Forest. Environmental Pollution, 158, 2527-2532.

McLaughlin SB, Nosal M, Wullschleger SD, Sun G (2007). Interactive effects of ozone and climate on tree growth and water use in a southern Appalachian forest in the USA. New Phytologist, 174, 109-124.

Miller PR, McBride JR (1999). Oxidant air pollution impacts in the montane forests of southern California-A case study of the San Bernardino Mountains_-Introduction. In: Miller PR, McBride JR eds. Oxidant Air Pollution Impacts in the Montane Forests of Southern California. Springer, New York.

Mills G, Hayes F, Simpson D, Emberson L, Norris D, Harmens H, Buker P (2011). Evidence of widespread effects of ozone on crops and (semi-) natural vegetation in Europe (1990-2006) in relation to AOT40- and flux-based risk maps. Global Change Biology, 17, 592-613.

Ministry of Water Resources, China (2006-2010). Bulletin of Flood and Drought Disasters in China. (in Chinese) [中国 水利部 (2006-2010). 中国水旱灾害公报.] http://www. mwr.gov.cn/zwzc/hygb/zgshzhgb/. Cited: 2016-6.

Mittler R, Zilinskas BA (1994). Regulation of pea cytosolic ascorbate peroxidase and other antioxidant enzymes during the progression of drought stress and following recovery from drought. Plant Journal, 5, 397-405.

Monakhova OF, Chernyadèv II (2002). Protective role of kartolin-4 in wheat plants exposed to soil draught. Applied Biochemistry and Microbiology, 38, 373-380.

Morgan PB, Ainsworth EA, Long SP (2003). How does elevated ozone impact soybean? A meta-analysis of photosynthesis, growth and yield. Plant, Cell \& Environment, 26, 1317-1328.

Nali C, Paoletti E, Marabottini R, Della Rocca G, Lorenzini G, Paolacci AR, Ciaffi M, Badiani M (2004). Ecophysiological and biochemical, strategies of response to ozone in Mediterranean evergreen broadleaf species. Atmospheric Environment, 38, 2247-2257.

National Bureau of Statistics of China (2007-2012). China Statistical Yearbook. China Statistics Press, Beijing. (in Chinese) [国家统计局 (2007-2012). 中国统计年鉴. 中国统计出版社, 北京.]

Nikolova PS, Andersen CP, Blaschke H, Matyssek R, Haeberle $\mathrm{K}-\mathrm{H}$ (2010). Belowground effects of enhanced tropospheric ozone and drought in a beech/spruce forest (Fagus sylvatica L./Picea abies (L.) Karst.). Environmental Pollu- tion, 158, 1071-1078.

Noctor G, Foyer CH (1998). Ascorbate and glutathione: Keeping active oxygen under control. Annual Review of Plant Physiology and Plant Molecular Biology, 49, 249-279.

Nonami H (1998). Plant water relations and control of cell elongation at low water potentials. Journal of Plant Research, 111, 373-382.

Oksanen E (2003). Responses of selected birch (Betula pendula Roth) clones to ozone change over time. Plant, Cell \& Environment, 26, 875-886.

Pääkkönen E, Seppänen S, Holopainen T, Kokko H, Kärenlampi S, Kärenlampi L, Kangasjärvi J (1998). Induction of genes for the stress proteins PR-10 and PAL in relation to growth, visible injuries and stomatal conductance in birch (Betula pendula) clones exposed to ozone and/or drought. New Phytologist, 138, 295-305.

Pandey D, Goswami C, Kumar B, Jain S (2001). Hormonal regulation of photosynthetic enzymes in cotton under water stress. Photosynthetica, 38, 403-407.

Panek JA (2004). Ozone uptake, water loss and carbon exchange dynamics in annually drought-stressed Pinus ponderosa forests: Measured trends and parameters for uptake modeling. Tree Physiology, 24, 277-290.

Panek JA, Goldstein AH (2001). Response of stomatal conductance to drought in ponderosa pine: Implications for carbon and ozone uptake. Tree Physiology, 21, 337-344.

Panek JA, Kurpius MR, Goldstein AH (2002). An evaluation of ozone exposure metrics for a seasonally drought-stressed ponderosa pine ecosystem. Environmental Pollution, 117, 93-100.

Paoletti E (2006). Impact of ozone on Mediterranean forests: A review. Environmental Pollution, 144, 463-474.

Paoletti E, Grulke NE (2010). Ozone exposure and stomatal sluggishness in different plant physiognomic classes. Environmental Pollution, 158, 2664-2671.

Parry MAJ, Andralojc PJ, Khan S, Lea PJ, Keys AJ (2002). Rubisco activity: Effects of drought stress. Annals of Botany, 89, 833-839.

Pasqualini S, Batini P, Ederli L, Porceddu A, Piccioni C, de Marchis F, Antonielli M (2001). Effects of short-term ozone fumigation on tobacco plants: Response of the scavenging system and expression of the glutathione reductase. Plant, Cell \& Environment, 24, 245-252.

Pearson M, Mansfield T (1993). Interacting effects of ozone and water stress on the stomatal resistance of beech (Fagus sylvatica L.). New Phytologist, 123, 351-358.

Pell EJ, Sinn JP, Eckardt N, Johansen CV, Winner WE, Mooney HA (1993). Response of radish to multiple stresses. 2. Influence of season and genotype on plantresponse to ozone and soil-moisture deficit. New Phytologist, 123, 153-163.

Pelloux J, Jolivet Y, Fontaine V, Banvoy J, Dizengremel P 
(2001). Changes in Rubisco and Rubisco activase gene expression and polypeptide content in Pinus halepensis M. subjected to ozone and drought. Plant, Cell \& Environment, 24, 123-131.

Pignocchi C, Fletcher JM, Wilkinson JE, Barnes JD, Foyer CH (2003). The function of ascorbate oxidase in tobacco. Plant Physiology, 132, 1631-1641.

Pirker KF, Reichenauer TG, Pascual EC, Kiefer S, Soja G, Goodman BA (2003). Steady state levels of free radicals in tomato fruit exposed to drought and ozone stress in a field experiment. Plant Physiology and Biochemistry, 41, 921-927.

Pollastrini M, Desotgiu R, Camin F, Ziller L, Gerosa G, Marzuoli R, Bussotti F (2014). Severe drought events increase the sensitivity to ozone on poplar clones. Environmental and Experimental Botany, 100, 94-104.

Pollastrini M, Desotgiu R, Camin F, Ziller L, Marzuoli R, Gerosa G, Bussotti F (2013). Intra-annual pattern of photosynthesis, growth and stable isotope partitioning in a poplar clone subjected to ozone and water stress. Water, Air, \& Soil Pollution, 224, 1761.

Pollastrini M, Desotgiu R, Cascio C, Bussotti F, Cherubini P, Saurer M, Gerosa G, Marzuoli R (2010). Growth and physiological responses to ozone and mild drought stress of tree species with different ecological requirements. Trees, 24, 695-704.

Potters G, de Gara L, Asard H, Horemans N (2002). Ascorbate and glutathione: Guardians of the cell cycle, partners in crime? Plant Physiology and Biochemistry, 40, 537-548.

Pretzsch H, Dieler J (2011). The dependency of the size-growth relationship of Norway spruce (Picea abies (L.) Karst.) and European beech (Fagus sylvatica L.) in forest stands on long-term site conditions, drought events, and ozone stress. Trees-Structure and Function, 25, 355-369.

Qiu HJ, Cao MM, Hao JQ, Wang YL, Wang YM (2013). Analysis the relationship between drought frequency and scale of China in 1950-2010. Scientia Geographica Sinica, 33, 576-580. (in Chinese) [邱海军, 曹明明, 郝俊 卿, 王赝林, 王彦民 (2013). 1950～2010年中国干旱灾 情频率-规模关系分析. 地理科学, 33, 576-580.]

Quartacci MF, Navari-Izzo F (1992). Water-stress and free-radical mediated changes in sunflower seedlings. Journal of Plant Physiology, 139, 621-625.

Rana G, Katerji N, Mastrorilli M (2012). Method for automatic determination of soybean actual evapotranspiration under open top chambers (OTC) subjected to effects of water stress and air ozone concentration. Environmental Monitoring and Assessment, 184, 6377-6394.

Rao MV, Koch JR, Davis KR (2000). Ozone: A tool for probing programmed cell death in plants. Plant Molecular Biology, 44, 345-358.

Renaut J, Bohler S, Hausman J-F, Hoffmann L, Sergeant K,
Ahsan N, Jolivet Y, Dizengremel P (2009). The impact of atmospheric composition on plants: A case study of ozone and poplar. Mass Spectrometry Reviews, 28, 495-516.

Retzlaff WA, Arthur MA, Grulke NE, Weinstein DA, Gollands B (2000). Use of a single-tree simulation model to predict effects of ozone and drought on growth of a white fir tree. Tree Physiology, 20, 195-202.

Ribas A, Penuelas J, Elvira S, Gimeno BS (2005). Contrasting effects of ozone under different water supplies in two Mediterranean tree species. Atmospheric Environment, 39, 685-693.

Sadras VO, Milroy SP (1996). Soil-water thresholds for the responses of leaf expansion and gas exchange: A review. Field Crops Research, 47, 253-266.

Sandermann H (1996). Ozone and plant health. Annual Review of Phytopathology, 34, 347-366.

Sanmartin M, Drogoudi PD, Lyons T, Pateraki I, Barnes J, Kanellis AK (2003). Over-expression of ascorbate oxidase in the apoplast of transgenic tobacco results in altered ascorbate and glutathione redox states and increased sensitivity to ozone. Planta, 216, 918-928.

Schubert SD, Suarez MJ, Pegion PJ, Koster RD, Bacmeister JT (2004). On the cause of the 1930s Dust Bowl. Science, 303, 1855-1859.

Schuppler U, He PH, John PCL, Munns R (1998). Effect of water stress on cell division and cell-division-cycle 2-like cell-cycle kinase activity in wheat leaves. Plant Physiology, 117, 667-678.

Sergeant K, Spiess N, Renaut J, Wilhelm E, Hausman JF (2011). One dry summer: A leaf proteome study on the response of oak to drought exposure. Journal of Proteomics, 74, 1385-1395.

Sharma PN, Malik CP (1993). Photosynthetic responses of groundnut to moisture stress. Photosynthetica, 29, 157160.

Shimizu H, Feng YW (2007). Ozone and/or water stresses could have influenced the Betula ermanii Cham. forest decline observed at Oku-Nikko, Japan. Environmental Monitoring and Assessment, 128, 109-119.

Showman RE (1991). A comparison of ozone injury to vegetation during moist and drought years. Journal of the Air \& Waste Management Association, 41, 63-64.

Šircelj H, Tausz M, Grill D, Batic F (2005). Biochemical responses in leaves of two apple tree cultivars subjected to progressing drought. Journal of Plant Physiology, 162, 1308-1318.

Sitch S, Cox PM, Collins WJ, Huntingford C (2007). Indirect radiative forcing of climate change through ozone effects on the land-carbon sink. Nature, 448, 791-794.

Skärby L, Ro-Poulsen H, Wellburn FAM, Sheppard LJ (1998). Impacts of ozone on forests: A European perspective. New Phytologist, 139, 109-122.

www.plant-ecology.com 
Sofo A, Tuzio AC, Dichio B, Xiloyannis C (2005). Influence of water deficit and rewatering on the components of the ascorbate-glutathione cycle in four interspecific Prunus hybrids. Plant Science, 169, 403-412.

Sun MX, Zu CL, Xu JN (2004). Advances research on the impact of drought on plant: A review. Journal of Anhui Agricultural Sciences, 32, 365-367, 384. (in Chinese) [孙梅 霞, 祖朝龙, 徐经年 (2004). 干旱对植物影响的研究进 展. 安徽农业科学, 32, 365-367, 384.]

Talbi S, Romero-Puertas MC, Hernandez A, Terron L, Ferchichi A, Sandalio LM (2015). Drought tolerance in a Saharian plant Oudneya africana: Role of antioxidant defences. Environmental and Experimental Botany, 111, 114-126.

Tanaka Y, Sano T, Tamaoki M, Nakajima N, Kondo N, Hasezawa S (2005). Ethylene inhibits abscisic acidinduced stomatal closure in Arabidopsis. Plant Physiology, 138, 2337-2343.

Tezara W, Mitchell V, Driscoll S, Lawlor D (1999). Water stress inhibits plant photosynthesis by decreasing coupling factor and ATP. Nature, 401, 914-917.

Tian HQ, Xu XF, Song X (2007). Drought impacts on terrestrial ecosystem productivity. Journal of Plant Ecology (Chinese Version), 31, 231-241. (in Chinese with English abstract) [田汉勤, 徐小锋, 宋霞 (2007). 干旱对陆地生 态系统生产力的影响. 植物生态学报, 31, 231-241.]

Tietz S, Wild A (1991). Investigations on the phosphoenolpyruvate carboxylase activity of spruce needles relative to the occurrence of novel forest decline. Journal of Plant Physiology, 137, 327-331.

Torsethaugen G, Pell EJ, Assmann SM (1999). Ozone inhibits guard cell $\mathrm{K}^{+}$channels implicated in stomatal opening. Proceedings of the National Academy of Sciences of the United States of America, 96, 13577-13582.

Vitale M, Salvatori E, Loreto F, Fares S, Manes F (2008). Physiological responses of Quercus ilex leaves to water stress and acute ozone exposure under controlled conditions. Water, Air, \& Soil Pollution, 189, 113-125.

Wagg S, Mills G, Hayes F, Wilkinson S, Cooper D, Davies WJ (2012). Reduced soil water availability did not protect two competing grassland species from the negative effects of increasing background ozone. Environmental Pollution, 165, 91-99.

Wallin G, Karlsson PE, Sellden G, Ottosson S, Medin EL, Pleijel H, Skarby L (2002). Impact of four years exposure to different levels of ozone, phosphorus and drought on chlorophyll, mineral nutrients, and stem volume of Norway spruce, Picea abies. Physiologia Plantarum, 114, 192-206.

Wang XL, Chen QC (1974). Plants as "atmospheric pollution monitoring alarm”. The Plant Journal, (4), 29-31. (in Chi- nese) [王勋陵, 陈庆诚 (1974). 利用植物作为大气污染 “监测警报器”. 植物学杂志, (4), 29-31.]

Watanabe M, Yonekura T, Honda Y, Yoshidome M, Nakaji T, Izuta $\mathrm{T}$ (2005). Effects of ozone and soil water stress, singly and in combination, on leaf antioxidative systems of Fagus crenata seedlings. Journal of Agricultural Meteorology, 60, 1105-1108.

Wellburn FAM, Lau KK, Milling PMK, Wellburn AR (1996). Drought and air pollution affect nitrogen cycling and free radical scavenging in Pinus halepensis (Mill). Journal of Experimental Botany, 47, 1361-1367.

Wen Z, Wang L, Wang XK, Li L, Cui J (2014). Combined effects of $\mathrm{O}_{3}$ and drought on leaf stomata of Acer truncatum. Chinese Journal of Ecology, 33, 560-566. (in Chinese with English abstract) [文志, 王丽, 王效科, 李丽, 崔健 (2014). $\mathrm{O}_{3}$ 和干旱胁迫对元宝枫叶片气孔特征的 复合影响. 生态学杂志, 33, 560-566.]

Wilkinson S, Davies WJ (2009). Ozone suppresses soil dryingand abscisic acid (ABA)-induced stomatal closure via an ethylene-dependent mechanism. Plant, Cell \& Environment, 32, 949-959.

Wilkinson S, Davies WJ (2010). Drought, ozone, ABA and ethylene: New insights from cell to plant to community. Plant, Cell \& Environment, 33, 510-525.

Wittig VE, Ainsworth EA, Long SP (2007). To what extent do current and projected increases in surface ozone affect photosynthesis and stomatal conductance of trees? A metaanalytic review of the last 3 decades of experiments. Plant, Cell \& Environment, 30, 1150-1162.

Wittig VE, Ainsworth EA, Naidu SL, Karnosky DF, Long SP (2009). Quantifying the impact of current and future tropospheric ozone on tree biomass, growth, physiology and biochemistry: A quantitative meta-analysis. Global Change Biology, 15, 396-424.

Xu H, Biswas DK, Li WD, Chen SB, Zhang L, Jiang GM, Li YG (2007). Photosynthesis and yield responses of ozonepolluted winter wheat to drought. Photosynthetica, 45, 582-588.

Xu H, Yang JC, Chen SB, Jiang GB, Li KY (2007). Review of plant responses to ozone pollution. Journal of Plant Ecology (Chinese Version), 31, 1205-1213. (in Chinese with English abstract) [许宏, 杨景成, 陈圣宾, 蒋高明, 李永 庚 (2007). 植物的臭氧污染胁迫效应研究进展. 植物生 态学报, 31, 1205-1213.]

Yang F, Miao LF, Xu Xiao, Li CY (2007). Progress in research of plant responses to drought stress. Chinese Journal of Applied and Environmental Biology, 13, 586-591. (in Chinese with English abstract) [杨帆, 苗灵风, 胥晓, 李春阳 (2007). 植物对干旱胁迫的响应研究进展. 应用与环境 生物学报, 13, 586-591.] 
Yao YQ, Liu XP, Li ZZ, Ma XF, Rennenberg H, Wang X, Li HC (2013). Drought-induced $\mathrm{H}_{2} \mathrm{O}_{2}$ accumulation in subsidiary cells is involved in regulatory signaling of stomatal closure in maize leaves. Planta, 238, 217-227.

Ye LH, Bao HY, Wang ZY, Lie GW, Chen HY, Zhang XP, Chen X, Ke H, Tian XQ, Tan JD (2014). Effects of ozone and drought on biomass allocation of four seedlings in South China. Advanced Materials Research, 864-867, 2478-2484.

Yonekura THY, Oksanen E, Yoshidome M, Watanabe M, Funada R KT, Izuta T (2001b). The influences of ozone and soil water stress, singly and in combination, on leaf gas exchange rates, leaf ultrastructural characteristics and annual ring width of Fagus crenata seedlings. Journal of Japan Society for Atmospheric Environment, 36, 333-351.

Yonekura T, Dokiya Y, Fukami M, Izuta T (2001a). Effects of ozone and/or soil water stress on growth and photosynthesis of Fagus crenata seedlings. Water, Air, \& Soil Pollu- tion, 130, 965-970.

Yonekura T, Yoshidome M, Watanabe M, Honda Y, Ogiwara I, Izuta $T$ (2004). Carry-over effects of ozone and water stress on leaf phenological characteristics and bud frost hardiness of Fagus crenata seedlings. Trees, 18, 581-588.

Zhang JX, Kirkham MB (1994). Drought-stress-induced changes in activities of superoxide-dismutase, catalase, and peroxidase in wheat species. Plant \& Cell Physiology, 35, 785-791.

Zhang JX, Kirkham MB (1996). Enzymatic responses of the ascorbate-glutathione cycle to drought in sorghum and sunflower plants. Plant Science, 113, 139-147.

Zhao MS, Running SW (2010). Drought-induced reduction in global terrestrial net primary production from 2000 through 2009. Science, 329, 940-943.

责任编委: 岳 明 责任编辑: 李 敏

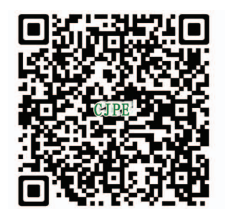

植物生态学报官网



微信订阅号

期刊及学科

相关信息发布

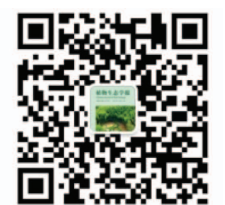

微信服务号

稿件状态查询

全文检索浏览 